OPEN ACCESS

Edited by:

John D. Imig,

Medical College of Wisconsin, USA

Reviewed by:

Victor Manuel Pulgar,

Wake Forest School of Medicine, USA

Brett M. Mitchell,

Texas A\&M Health Science Center,

USA

*Correspondence:

Amanda N. Sferruzzi-Perri ans48@cam.ac.uk

Specialty section:

This article was submitted to Vascular Physiology

a section of the journal

Frontiers in Physiology

Received: 11 December 2015

Accepted: 25 January 2016

Published: 14 March 2016

Citation:

Sferruzzi-Perri AN and Camm EJ

(2016) The Programming Power of the

Placenta. Front. Physiol. 7:33.

doi: 10.3389/fphys.2016.00033

\section{The Programming Power of the Placenta}

\author{
Amanda N. Sferruzzi-Perri ${ }^{*}$ and Emily J. Camm \\ Department of Physiology, Development and Neuroscience, University of Cambridge, Cambridge, UK
}

Size at birth is a critical determinant of life expectancy, and is dependent primarily on the placental supply of nutrients. However, the placenta is not just a passive organ for the materno-fetal transfer of nutrients and oxygen. Studies show that the placenta can adapt morphologically and functionally to optimize substrate supply, and thus fetal growth, under adverse intrauterine conditions. These adaptations help meet the fetal drive for growth, and their effectiveness will determine the amount and relative proportions of specific metabolic substrates supplied to the fetus at different stages of development. This flow of nutrients will ultimately program physiological systems at the gene, cell, tissue, organ, and system levels, and inadequacies can cause permanent structural and functional changes that lead to overt disease, particularly with increasing age. This review examines the environmental regulation of the placental phenotype with particular emphasis on the impact of maternal nutritional challenges and oxygen scarcity in mice, rats and guinea pigs. It also focuses on the effects of such conditions on fetal growth and the developmental programming of disease postnatally. A challenge for future research is to link placental structure and function with clinical phenotypes in the offspring.

Keywords: placenta, fetus, programming, maternal environment, pregnancy, nutrient transport

In the late 1980's, the epidemiologist and clinician David Barker found an unexpected link between low birth weight, an indicator of poor nutrition during pregnancy, and an increased risk of heart disease in adulthood. Barker and colleagues hypothesized over a series of studies that an adverse fetal environment followed by plentiful food in the postnatal period may lead to adult chronic disease (Barker and Osmond, 1986; Barker et al., 1989, 1993). Opponents of Barker's hypothesis argued that early nutrition was inferred indirectly from fetal and infant growth, and that most of the epidemiological studies were also vulnerable to confounding factors, particularly social class, that influence both the intrauterine and adult environments. Epidemiological studies arising from the Dutch famine of 1944 were a key test of Barker's hypothesis. Babies exposed to the famine during gestation were found to more likely to suffer from obesity, type 2 diabetes, cognitive deficits and heart disease, as well as die earlier as adults (Barker, 2004a,b,c; de Rooij et al., 2010). Whilst Barker's concept was initially controversial, an explosion of studies across a variety of human populations and experimental animals exposed to various insults during gestation showed that, in addition to metabolic and cardiovascular diseases, other chronic conditions such as cancer, allergies, asthma and neurocognitive disorders are also predetermined by the environment experienced in the womb and observed across the normal continuum of birth weights (McMillen and Robinson, 2005; Hanson and Gluckman, 2008; Rees et al., 2008; Susser and St Clair, 2013). Thus, there has been a revolutionary shift in thinking about how human qualities, such as appetite and metabolism, intelligence, temperament and susceptibility to disease are determined, and when they begin to develop. Moreover, there has been a drive to better identify the factors controlling intrauterine growth that are important in early-life programming of health in later life. 
The main determinant of intrauterine growth is the placental supply of maternal nutrients and oxygen to the fetus. Indeed, in many species fetal weight near term and/or birth weight positively correlate with placental weight, and these associations have been suggested to serve as an indicator of the placental capacity to support fetal growth (Fowden et al., 2009). However, during pregnancy the placenta is exposed to a variety of environmental signals which can alter placental formation, and thus, the association of fetal weight to placental weight. Total food intake and macro- and micro-nutrient composition can vary during pregnancy due to seasonal changes in food availability, food fads or aversions and/or poor nutritional awareness about the harmful effects of cheap processed foods that are rich in sugar and fat (Vaughan et al., 2012a). Moreover, oxygen levels can be low in pregnancies at sea level due to cigarette smoking, maternal anemia, cord occlusion or poor placental vascularization, as well as in all pregnancies at high altitude (Zamudio, 2003; Hutter et al., 2010; Tissot van Patot et al., 2010). Attempts to emulate such conditions experimentally in animals, including mice, rats and guinea pigs, have shown that placental and fetal weights are altered (Table 1). In general, these studies show that the specific effects on placental and fetal weights appear to depend on the type of challenge (altered nutritional or oxygen availability, or both), the severity of the challenge and the duration and timing of the challenge in relation to formation of the placenta.

\section{REGULATION OF FETAL AND PLACENTAL WEIGHTS BY THE MATERNAL ENVIRONMENT}

Reducing maternal food intake by $15-50 \%$ for the majority of pregnancy in mice and rats, or prior to and during pregnancy in guinea pigs, results in fetal and placental weights that are, on average, 22-26\% lower than ad libitum controls (Ahokas et al., 1981, 1983; Sohlstrom et al., 1998a,b; Roberts et al., 2001; Caminos et al., 2008; Coan et al., 2010; Ganguly et al., 2012; Mayeur et al., 2012; Schlitt and Schulz, 2012; Schulz et al., 2012; Soo et al., 2012; Table 1). In the guinea pig, the capacity of the mother to deliver nutrients to the fetus is further impaired if maternal nutrient reserves are depleted by undernutrition prior to conception (Sohlstrom et al., 1998a,b, 2001; Roberts et al., 2001). Thus, poor intrauterine growth is likely to be of early onset in this model. When assessing the studies summarized in Table 1, the greatest reductions in feto-placental growth are reported for pregnant mice, and are also observed if the nutrient restriction occurred from mid-gestation (Ganguly et al., 2012). Fetal growth rate for the mouse is much higher than for most species, including rats and guinea pigs (Fowden and Moore, 2012), and may therefore be more sensitive to changes in nutrient supply. Low-protein isocalorific diets for most of pregnancy also reduce fetal weight by $\sim 18 \%$ near term in mice and rats, highlighting the importance of dietary protein for fetal tissue accretion (Rosso, 1977a,b; Varma and Ramakrishnan, 1991; Malandro et al., 1996a; Doherty et al., 2003; Jansson et al., 2006; Rutland et al., 2007; Vieira-Filho et al., 2009; Coan et al., 2011; Rosario et al., 2011; Gao et al., 2012a,b, 2013; Liu et al., 2014; Table 1). However, depending on the degree of protein deprivation and the source of the extra carbohydrate used to maintain the calorific content of the diet, low-protein diets have been associated with reduced, increased or unchanged placental weight in near-term rodents (Table 1). If global undernutrition or protein deprivation occurs solely in the second half of pregnancy, fetal weight is reduced even though placental weight may be unchanged (Franko et al., 2009; Gheorghe et al., 2009; Richter et al., 2009; Higgins et al., 2015; Table 1). This suggests that gross growth of the rodent placenta exhibits a degree of resilience to short-term nutritional insults once it has formed. There may also be catch-up growth of the placenta in late gestation if the nutritionally-deprived dams are returned to ad libitum feeding of the control diet. For instance, the effect of global undernutrition to reduce placental weight was mitigated by ad libitum feeding of the dam in late pregnant mice (Harper et al., 2015). This suggests alterations in the placenta caused by nutrient restriction in early pregnancy could be reversible.

Excess calories delivered through diets high in fat, simple sugars, or both, for months prior to and during pregnancy have varying effects on feto-placental growth in mice and rats. Diets with 2.5 to 6-times the fat content of control chow tend to increase fetal weight, often in the absence of changes in placental weight (Jones et al., 2008; Rebholz et al., 2011; Qiao et al., 2012; Gaccioli et al., 2013; Li et al., 2013; Mazzucco et al., 2013; Dahlhoff et al., 2014; Kim et al., 2014; Wang et al., 2015). However, when dietary fat content exceeds 6-times control values, or high-fat diets are consumed for several months prior to conception, fetal and placental weights are often decreased (Taylor et al., 2003; Liang et al., 2009a, 2010; Jungheim et al., 2010; Hayes et al., 2012, 2014; King et al., 2013; Bellisario et al., 2015a,b; Reynolds et al., 2015; Wu et al., 2015). The reduction in conceptus growth in these studies may be secondary to the systemic inflammatory state in, and/or a greater competition for resources by, the pre-conceptionally chronically obese dam. When high-fat diets are fed from day 1 of pregnancy, fetal weight is unaltered or marginally reduced, with both increased and reduced placental weights reported depending on whether simple sugars or fiber were additionally consumed in excess (Gallou-Kabani et al., 2010; Lin et al., 2011; Mark et al., 2011; Gabory et al., 2012; SferruzziPerri et al., 2013; Qiao et al., 2015). In rodents, increasing the proportion of energy intake from sugar, either by adding fructose to their drinking water or by supplying sweetened condensed milk, has been associated with both unchanged and reduced fetal and placental weights depending on the length of exposure (before, during or part of pregnancy) and whether gross maternal food intake was reduced (Holemans et al., 2004; Vickers et al., 2011; Gray et al., 2013; Mukai et al., 2013; Lager et al., 2014). Rodents exhibit tight homeostatic control of their energy intake (Keesey and Hirvonen, 1997), and the contribution of the reduced protein and/or micronutrient intake to the effects of calorie-dense diets on feto-placental phenotype requires clarification (Armitage et al., 2004). Embryo transfers between mice fed a control or high-fat diet prior to pregnancy have shown that the effect of pre-conception obesity and an adverse metabolic milieu on feto-placental growth is not mitigated by a control diet during gestation, indicating permanent effects on development 


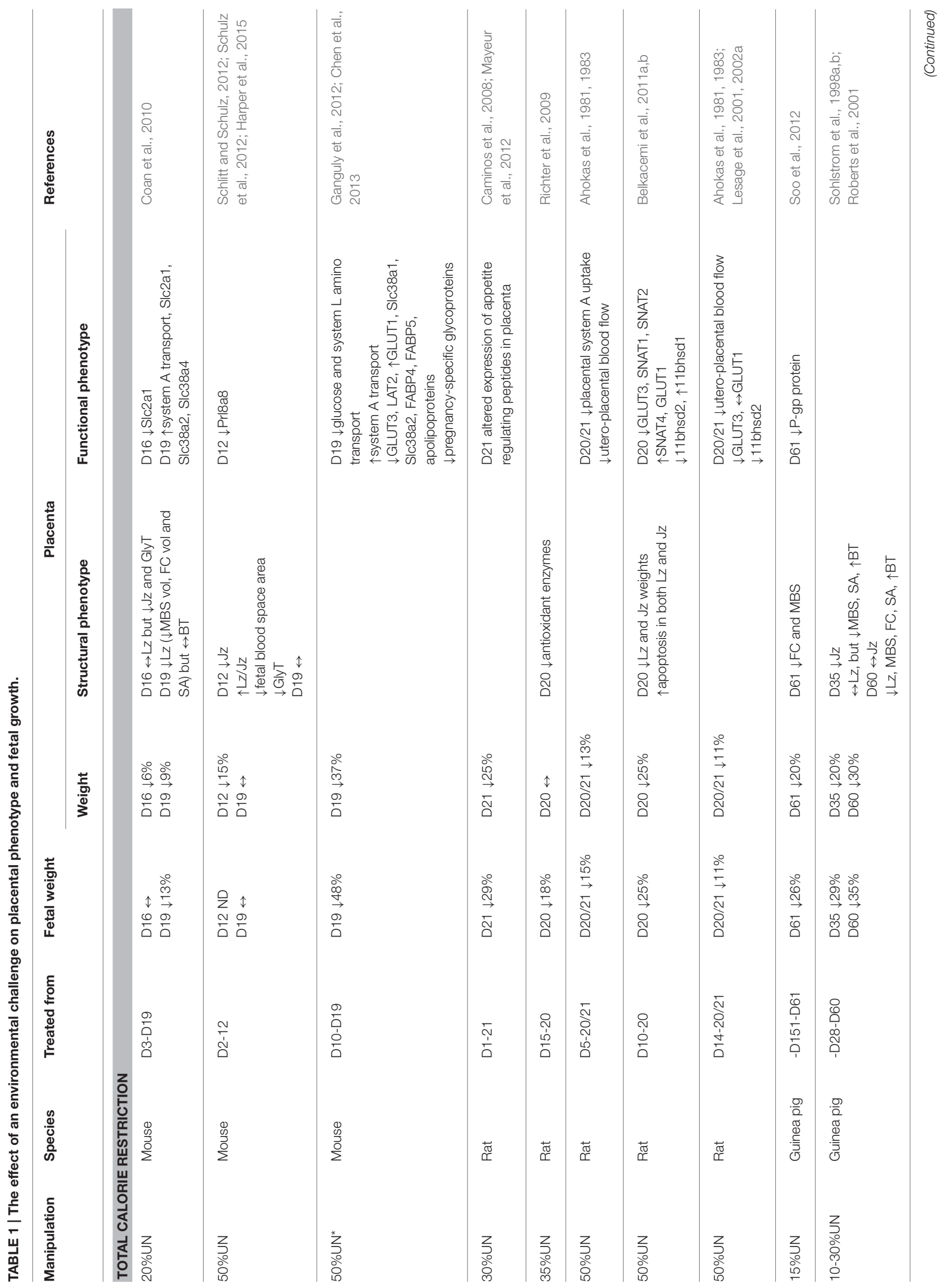




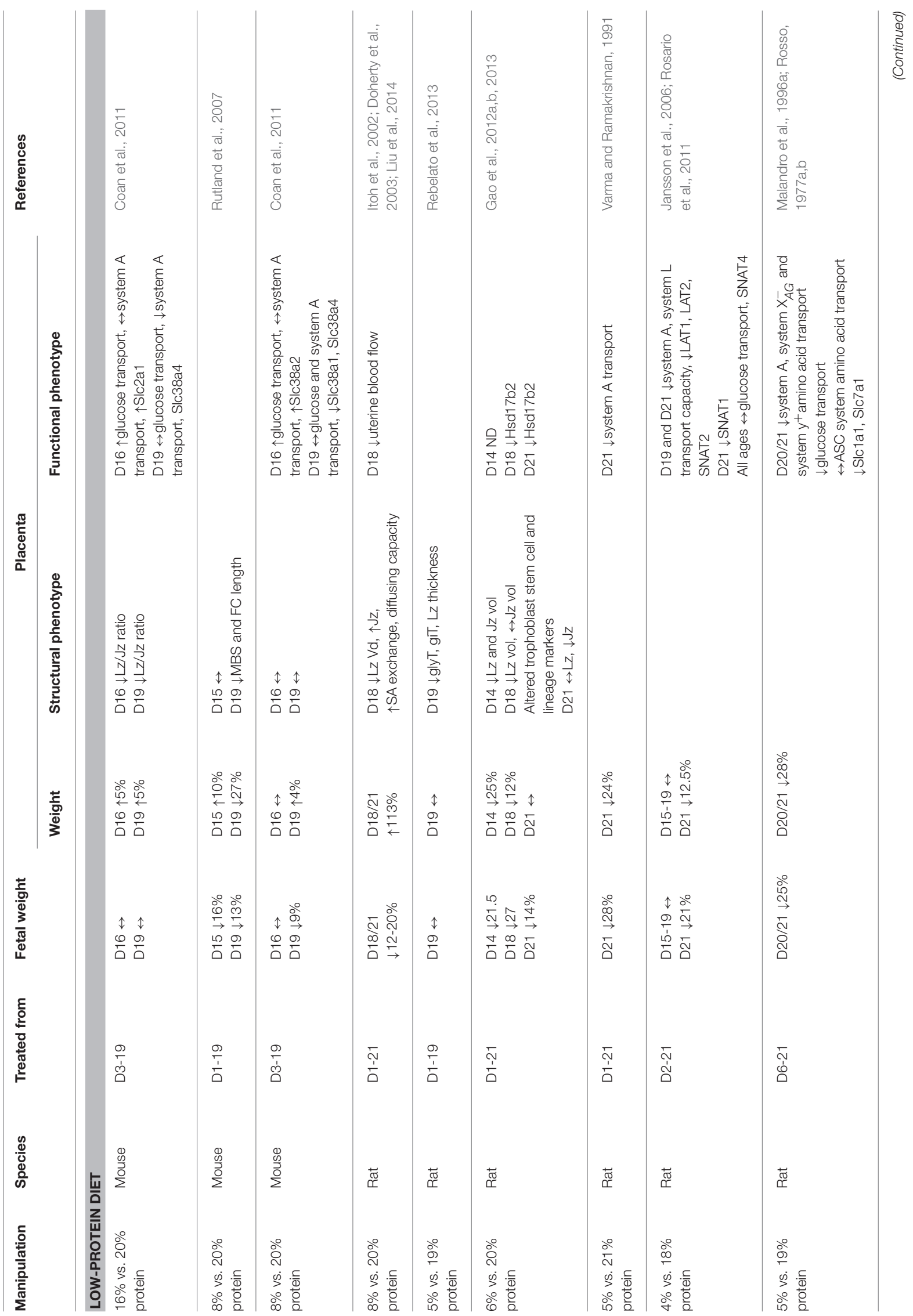




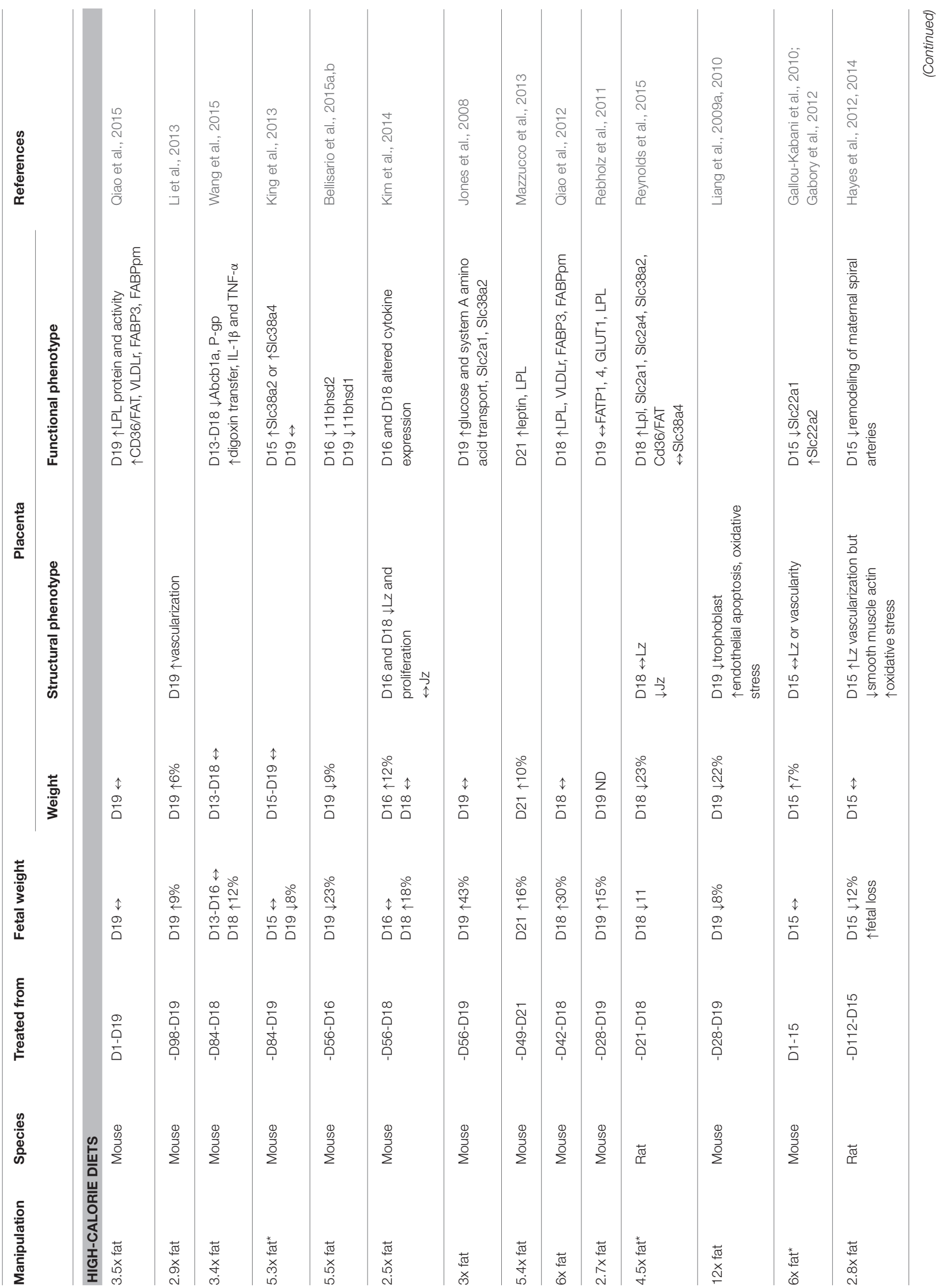


Sferruzzi-Perri and Gam

The Placenta and Developmental Programming

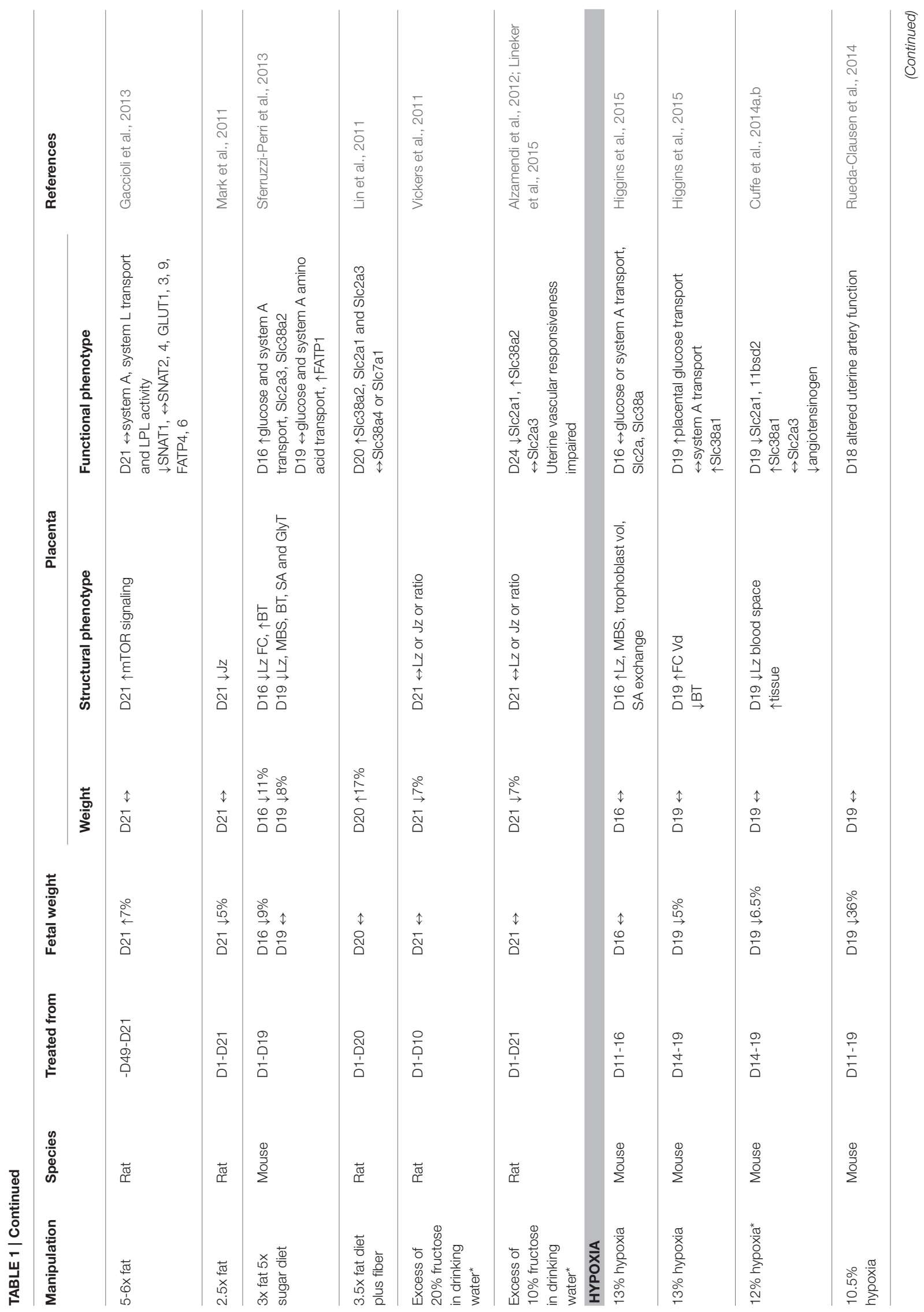

Frontiers in Physiology | www.frontiersin.org

March 2016 | Volume 7 | Article 33 


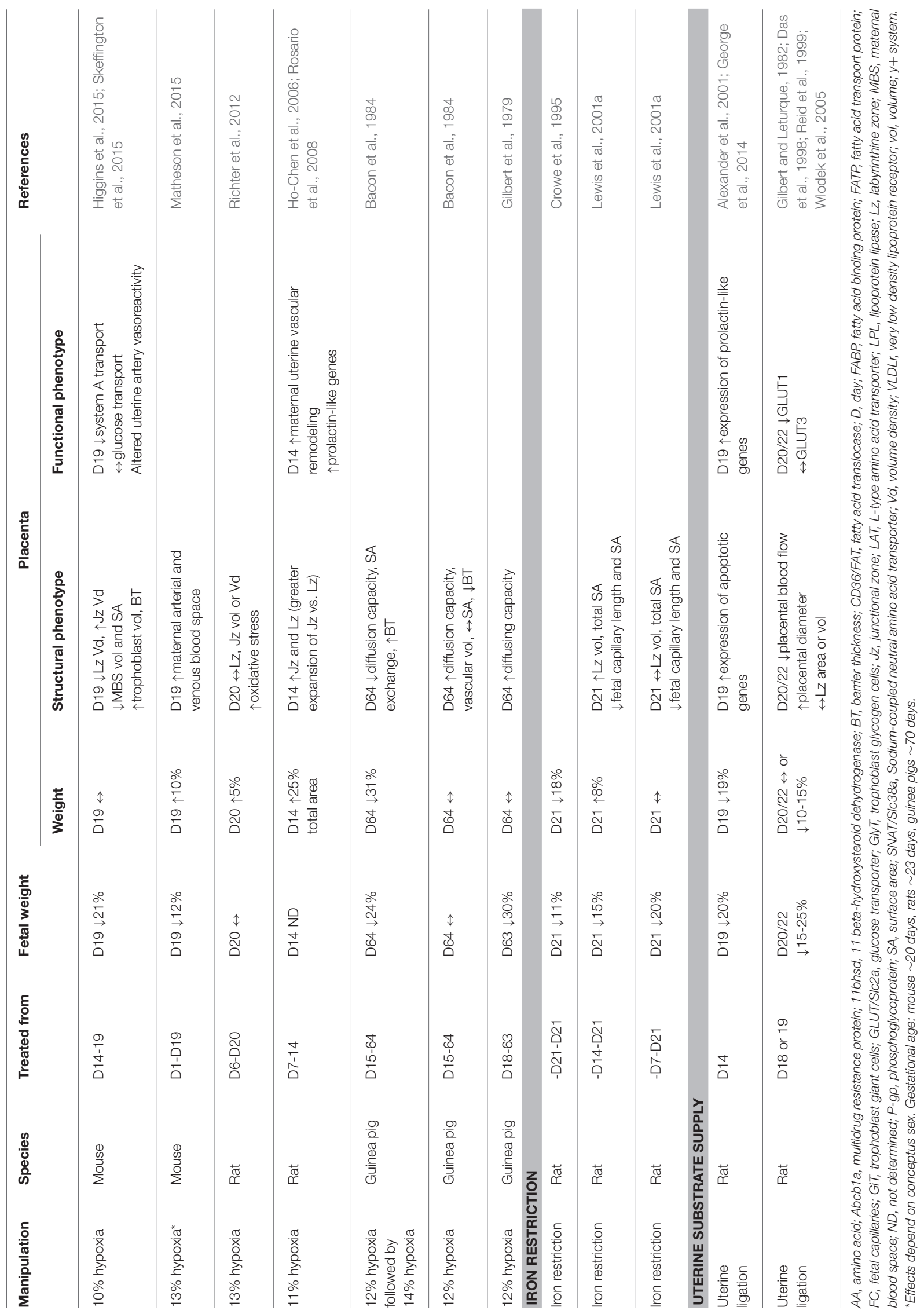


(Sasson et al., 2015). Maternal oocyte quality and conceptus metabolism are altered in rodents that are obese or fed diets with altered nutrient composition pre-gestationally (Minge et al., 2008; Mitchell et al., 2009; Igosheva et al., 2010; Jungheim et al., 2010; Luzzo et al., 2012). Moreover, maternal protein deprivation for as short as 4 days post-conception is sufficient to influence the allocation of trophectoderm and inner cell mass cells within the rodent blastocyst, as well as trophoblast cell proliferation and differentiation with consequences for subsequent development of the definitive placenta and the fetus (Kwong et al., 2000, 2006; Watkins et al., 2008, 2015). Conceptus weight in the latter part of gestation therefore, reflects the availability of specific nutrients before and during pregnancy; from the earliest stages of development and cell lineage determination through to the metabolic and morphological modifications of the fetus and placenta that occur toward term.

Reduced oxygen availability induced by housing animals in chambers where the inflow of oxygen is displaced by nitrogen, also affects conceptus growth. In mice, rats and guinea pigs, fetal growth is reduced in a severity-dependent fashion, suggesting fetal growth is highly sensitive to alterations in atmospheric oxygen content (Table 1). For instance, fetal weight is unaltered by $16 \%$ inspired maternal oxygen, reduced on average by $\sim 10 \%$ with $12-13 \%$ oxygen and restricted by $>22 \%$ in association with fetal loss if atmospheric oxygen drops to $<11 \%$ in pregnant mice, rats and/or guinea pigs (Gilbert et al., 1979; Bacon et al., 1984; Lueder et al., 1995; Richter et al., 2012; Cuffe et al., 2014a; RuedaClausen et al., 2014; Higgins et al., 2015; Matheson et al., 2015). In mice and guinea pigs, fetal growth is most adversely affected if the hypoxic challenge occurs in the last third of pregnancy when fetal growth is maximal. In contrast to the fetus, maternal inhalation hypoxia does not reduce placental weight and can cause placentomegaly if the hypoxic challenge commences within the first third of gestation. Placentomegaly may be secondary to a hypoxia-induced increase in trophoblast invasion of the maternal decidua (Alam et al., 2007; Rosario et al., 2008; Chakraborty et al., 2011) as this process mediates both circumferential expansion of, and maternal blood flow to, the placenta. Pregnant rodents and guinea pigs exposed to severe hypoxic atmospheres have been reported to reduce their food intake, and therefore the resultant effects on the feto-placental phenotype may be partly attributable to maternal hypophagia (Bacon et al., 1984; Camm et al., 2010, 2011; Higgins et al., 2015; Matheson et al., 2015). In rats, anemia induced by nutritional deficiency of iron prior to pregnancy reduces fetal weight, with variable effects on placental weight depending on the length of exposure and strain of rat (Crowe et al., 1995; Lewis et al., 2001a). In rats and guinea pigs, when both nutrient and oxygen availability to the conceptus are reduced by uterine artery ligation, fetal and placental growth tend to be restricted to a greater degree than observed with hypoxia and maternal food deprivation alone (Gilbert and Leturque, 1982; Das et al., 1998; Reid et al., 1999; Alexander et al., 2001; Carter et al., 2005; Wlodek et al., 2005; Turner and Trudinger, 2009; George et al., 2014). To date, only one study has been performed in the mouse, and showed reduced fetal growth in the absence of a change in placental weight near term when uterine blood flow is reduced by $40 \%$ (Intapad et al., 2014).
Thus, environmentally-induced alterations in the ability of the mother to supply nutrients and oxygen both prior to and during pregnancy, affect fetal and placental growth.

Generally, an adverse maternal environment will have a greater influence on fetal than placental growth (Table 1), suggesting that the placenta may be spared over other organs (Vaughan et al., 2012a). However, in cases of environmentallyinduced fetal overgrowth, fetal changes occur without a change in placental weight, suggesting enhanced placental efficiency in supporting growth (Jones et al., 2008; Rebholz et al., 2011; Gaccioli et al., 2013; Li et al., 2013; Mazzucco et al., 2013; Dahlhoff et al., 2014; Kim et al., 2014; Wang et al., 2015). When the growth kinetics of the conceptus in resource-limited rodents pregnancies have been assessed, it appears that alterations in placental weight occur before noticeable retardation of fetal growth (Coan et al., 2010; Sferruzzi-Perri et al., 2011; Kim et al., 2014). For instance, fetal growth is maintained until at least day 16 in undernourished pregnant mice, even though placental weight is reduced at this gestational age (Coan et al., 2010; Sferruzzi-Perri et al., 2011). Furthermore, with some nutritional manipulations the placenta is more adversely affected than the fetus near term (Rutland et al., 2007; Liang et al., 2009a, 2010; Sferruzzi-Perri et al., 2013; Reynolds et al., 2015). Indeed, in mice fed obesogenic diets high in sugar and fat during pregnancy, fetuses attain a normal body weight near term despite the persistence of reduced placental weight and increased maternal adiposity (SferruzziPerri et al., 2013). Thus, environmental challenges can affect the relationship of fetal weight to placental weight, and suggest that in some instances, the placenta may adapt its capacity to optimize fetal growth and survival in the prevailing conditions in utero (Fowden et al., 2009). Such changes in placental phenotype could be exerted at a morphological and/or functional level.

\section{REGULATION OF PLACENTAL STRUCTURE BY THE MATERNAL ENVIRONMENT}

Changes in placental capacity to support fetal growth could be generated by environmentally-induced alterations in the gross structure of the placenta, conferring a functional advantage. In rodents and guinea pigs, the placenta is organized into discrete regions that function predominately in materno-feto transport and hormone production; the labyrinthine zone and junctional/interlobium zone, respectively. These zones have a different tempo of development and maturation. In some environmental manipulations, both regions are proportionately altered and track with near-term placental weight (Wlodek et al., 2005; Belkacemi et al., 2011a; Table 1). However, in many studies the two regions respond differently to the environmental manipulation (Table 1). For instance, in rats the formation of the junctional zone is specifically reduced by a maternal highfat diet and in undernourished mice and guinea pigs the volume of junctional/interlobium zone is decreased earlier in gestation than that of the labyrinthine zone (Roberts et al., 2001; Coan et al., 2010; Mark et al., 2011; Sferruzzi-Perri et al., 2011; Schulz et al., 2012). These studies suggest that there may be an active 
preservation of placental transport function, even at the expense of placental endocrine region formation, to optimize substrate delivery to the fetus at particular phase/s of development. However, in mice fed a low-protein diet or calorific-dense diets with altered protein content, this labyrinthine zone sparing is not observed and the labyrinthine zone is more adversely affected than the junctional zone, which would limit the provision of nutrients to the fetus (Doherty et al., 2003; Coan et al., 2011; Rebelato et al., 2013; Sferruzzi-Perri et al., 2013; Kim et al., 2014).

The severity of maternal oxygen deprivation also affects the gross morphology of the placenta. Maternal iron-depletion or $12-13 \%$ inhalation hypoxia in the last third of pregnancy selectively expanded the labyrinthine zone, which would optimize materno-fetal substrate delivery (Lewis et al., 2001a; Cuffe et al., 2014a; Higgins et al., 2015). Conversely, if maternal inspired oxygen is lowered to $10 \%$, the labyrinthine zone is reduced with a concomitant increase in the volume density of the junctional zone (Rosario et al., 2008; Higgins et al., 2015). Switching conceptus metabolism from aerobic to anaerobic by inhibiting mitochondrial oxidation early in blastocyst development also alters placental formation in rats near term (Wakefield et al., 2011). Environmentally-induced changes in the gross architecture of the placenta have been linked to altered expression of genes and proteins involved in proliferation, apoptosis, oxidative stress and cell lineage differentiation (Kwong et al., 2000; Gheorghe et al., 2007, 2009; Liang et al., 2009a, 2010; Richter et al., 2009; Belkacemi et al., 2011b; Chen et al., 2013; Gao et al., 2013; Kim et al., 2014; Matheson et al., 2015; Watkins et al., 2015). Thus, regions in the placenta dedicated to transport and endocrine function appear differentially sensitive to changes in the maternal supply of nutrients and oxygen. Such changes depend on the type and timing of the insult, and the species examined.

Maternal environmental manipulations can also alter the ultrastructure of the placental transport region. Following maternal caloric restriction in the guinea pig, and severe maternal oxygen deprivation (10\%) in the mouse, the thickness of the trophoblast barrier between the maternal and fetal circulations is increased, and the surface area for exchange and density of fetal capillaries and/or maternal blood spaces diminished (Roberts et al., 2001; Soo et al., 2012; Hvizdosova-Klescova et al., 2013; Higgins et al., 2015). Placental fetal capillary length and surface area is reduced, and the integrity and normal developmental architectural rearrangements of the fetal vasculature and maternal blood spaces decreased, following exposure to low-iron or low-protein diets, or global nutrient restriction (Lewis et al., 2001a; Rutland et al., 2007; Schulz et al., 2012). Such perturbations in the placental transport region will further limit substrate transfer, particularly by flowlimited passive diffusion processes (Fowden et al., 2006). There are, however, also beneficial changes that occur in placental morphology following a maternal environmental challenge (Table 1). For instance, the surface area for exchange and the diffusing capacity are increased in the overgrown placenta of protein-deprived rat dams (Doherty et al., 2003). Moreover, the interhemal barrier is thinner, and the exchange surface area and proportions of maternal and/or fetal blood compartments within the placenta are increased in mice and guinea pigs exposed to 12-13\% hypoxia (Gilbert et al., 1979; Bacon et al., 1984; Higgins et al., 2015; Matheson et al., 2015). These structural modifications will increase the placental capacity for materno-fetal diffusion and suggest placental adaptation. There are also gestational-age dependent alterations in placental fine architecture with maternal environmental manipulation that track with changes in fetal growth. For instance, the placental interhemal membrane barrier is thicker and vascularization reduced on day 16 of gestation when fetuses are growth restricted, in mouse dams consuming a diet high in both sugar and fat (Sferruzzi-Perri et al., 2013). However, by day 19 of pregnancy, these structural changes improve (thinner barrier) or are restored to control values (vascularization), in line with the normalization of fetal weight (Sferruzzi-Perri et al., 2013). In many of the environmentallymanipulated pregnancies, there are also changes in uterine vascular responsiveness and/or trophoblast remodeling of the maternal spiral arteries which have implications for blood flow and the delivery of substrates to the placenta (Ahokas et al., 1981, 1983; Itoh et al., 2002; Taylor et al., 2003; Alam et al., 2007; Rosario et al., 2008; Chakraborty et al., 2011; Hayes et al., 2012, 2014; Rueda-Clausen et al., 2014; Lineker et al., 2015; Skeffington et al., 2015). Thus, maternal nutritional challenges and oxygen availability affect the composition of the materno-fetal interface, which will have ramifications for placental substrate transport and thus fetal growth.

\section{REGULATION OF PLACENTAL TRANSPORT FUNCTION BY THE MATERNAL ENVIRONMENT}

Along with oxygen, glucose, amino acids and fatty acids represent essential nutrients for fetal growth. The placenta transports these substrates to the fetus by passive diffusion, transportermediated processes and endocytosis-exocytosis (Sibley et al., 1997; Duttaroy, 2009). Molecules like oxygen, carbon dioxide and urea traverse the placenta by passive diffusion. Glucose and lactate are transported down their concentration gradient by facilitated diffusion using transporter proteins embedded in the plasma membrane, without a requirement for additional energy. Amino acids are actively transported against their concentration gradient, using both membrane transporter proteins and the input of additional energy. Materno-fetal transfer of fatty acids is less understood although it involves the release of fatty acids from maternal triglycerides using lipases and the coordinated action of both cytoplasmic and membrane carrier proteins for diffusion. In addition to morphological characteristics of the placenta, transporter-mediated processes are influenced by the expression, localization, affinity and activity of specific transporters in the placental plasma membranes as well as the materno-fetal concentration gradient across the placenta (Hay, 1995; Jansson and Powell, 2006). Changes in any of these placental parameters can, therefore, affect fetal fuel acquisition and growth with consequences for adult health and disease (Fowden et al., 2008).

The maternal environment modifies placental glucose transport capacity (Table 1). Trans-placental transfer of glucose 
in vivo is unaltered by under-nourishing pregnant mice to $80 \%$ of the ad libitum daily intake. However, when maternal total food intake is reduced to $50 \%$ of ad libitum values, trans-placental transfer of glucose near term is diminished by $\sim 40 \%$ (Coan et al., 2010; Ganguly et al., 2012). In rats, glucose transfer is also diminished if the protein content of the maternal diet is as low as 5\% (Rosso, 1977a), but unaltered by a $4 \%$ protein diet (Jansson et al., 2006). Reductions in glucose transfer will further deprive the fetus of this important metabolic fuel and likely exacerbate the effects of maternal dietary manipulations on fetal growth. However, in mice trans-placental glucose transfer is increased in late gestation when the protein deprivation is less severe, with 8 and 16\% protein diets (Coan et al., 2011), suggesting that the placenta may be trying to compensate for a deficit in the supply of another nutrient. In rodents near term, placental expression of the glucose transporter Slc2a3/GLUT3 is typically reduced by maternal undernutrition, whilst expression of Slc2a1/GLUT1 appears to increase under nutrient scarcity (Lesage et al., 2002a; Coan et al., 2010, 2011; Belkacemi et al., 2011a; Ganguly et al., 2012). Combined, these data indicate the differential responsiveness of specific transporter subtypes in the placenta following maternal nutritional manipulation. Excess dietary calories can also affect glucose transport. For instance in mice, materno-fetal clearance of glucose is increased near term by diets high in fat alone, as well as on day 16 of gestation in those also consuming excess sugar (Jones et al., 2008; Sferruzzi-Perri et al., 2013). Such changes were associated with increased expression of Slc2a1/GLUT1 and Slc2a3/GLUT3 by the placenta, respectively. In rats, high-fat diets with an altered fiber content during pregnancy also enhance placental expression of Slc2a1/GLUT1 and/or Slc2a3/GLUT3 just prior to delivery (Lin et al., 2011), whereas placental Slc2a1/GLUT1 is instead reduced by high dietary sugar intake (Alzamendi et al., 2012). Whether in vivo placental glucose transfer is altered in these studies however, is unknown. Exposure to $13 \%$ inspired oxygen for 5 days from pregnancy day 14, also increases placental uptake and clearance of glucose in mice, which suggests that glucose becomes a more important metabolic substrate in feto-placental tissues when oxygen availability is limited near term (Higgins et al., 2015). Certainly, in hypoxic pregnant rats, glucose uptake and lactate production by the fetuses is increased, suggesting glycolytic metabolism in the fetuses which would maintain the supply of energy for fetal growth (Lueder et al., 1995). However, $10 \%$ inspired oxygen does not affect placental uptake and trans-placental glucose transport in mice on day 19 and results in severe fetal growth restriction (Higgins et al., 2015). In rats where both nutrient and oxygen delivery to the conceptus is restricted by maternal uterine artery ligation, Slc2a1/GLUT1 is selectively reduced in the placenta (Das et al., 1998). Thus, placental glucose transfer is sensitive to maternal environmental manipulation but the specific response elicited is insult, severity and speciesdependent, and may optimize or further compromise conceptus growth in the prevailing condition.

The capacity of the placenta to deliver amino acids to the fetus is also modified by the maternal environment (Table 1). In rats consuming diets that contain $4-5 \%$ protein, the activity of the Systems A, L, $\mathrm{X}^{-\mathrm{AG}}$ and $\mathrm{y}^{+}$are diminished near term, in association with altered expression of Slc38a1/SNAT1, Slc7a5/LAT1, Slc7a8/LAT2 and Slc1a1/EAAC1, and Slc7a1/CAT1 amino acid transporters (Rosso, 1977b; Malandro et al., 1996a,b; Jansson et al., 2006; Rosario et al., 2011). These functional perturbations will further limit the supply of neutral, anionic and cationic amino acids to the fetus and contribute to the intrauterine growth restriction reported. Indeed, in this species down-regulation of System $\mathrm{A}$ and $\mathrm{L}$ amino acid transport precedes the onset of fetal growth restriction in dams fed the $4 \%$ protein diet (Jansson et al., 2006), and partial inhibition of System A activity in vivo induces fetal growth restriction in late gestation (Cramer et al., 2002), signifying the importance of amino acid transport for prenatal development. Placental System A transporter activity is also diminished near term in mice fed a $16 \%$ protein diet, but is instead unaltered by a more severe reduction to $8 \%$ dietary protein (Coan et al., 2011). The expression of Slc38a4/SNAT4 is reduced by both protein manipulations in the mouse placenta near term, although placental expression of the higher affinity System A transporter, Slc38a2/SNAT2 is increased in mice fed the $8 \%$, but not $16 \%$ protein diet compared to controls (Strakovsky et al., 2010; Coan et al., 2011). Altering the calorie intake of rodents also affects amino acid transport capacity. Feeding mice dams 50\% of ad libitum food intake from mid-gestation reduces placental System $\mathrm{L}$ activity just prior to term, in line with decreased Slc7a8/LAT2 abundance. However, in these mice (50\% undernutrition) and those fed $80 \%$ of ad libitum food intake, transfer of amino acids via System A is adaptively increased near term and is coupled with enhanced placental Slc38a1/SNAT1 and/or Slc38a2/SNAT2 expression (Coan et al., 2010; Sferruzzi-Perri et al., 2011; Ganguly et al., 2012). Mice consuming high-calorie fat diets with and without excess sugar also show enhanced placental System A activity in association with elevated Slc38a2/SNAT2 expression and accelerated fetal growth (Jones et al., 2008; Sferruzzi-Perri et al., 2013). Slc38a2/SNAT2 expression is also increased in the placenta of rats fed high sugar or fat diets (Lin et al., 2011; Alzamendi et al., 2012). However, in another rat study, Slc38a1/SNAT1 abundance was decreased by a high-fat diet with no change in placental System A capacity in vivo (Gaccioli et al., 2013). Capacity of the placenta for amino acid transport is also responsive to changes in maternal oxygen availability. Inhalation hypoxia at $10 \%$, but not $13 \%$, adversely affects placental System A transport in vivo in near-term mice. This alteration appears to be related to the reduction in maternal food intake and the inability of the placenta to maintain an energy supply for the active transport of amino acids, specifically in the $10 \%$ hypoxia group (Higgins et al., 2015). Thus, the fetal provision of nutrients may also be decreased as a secondary effect of reduced maternal oxygen availability on placental transport capacity. Indeed, fetal concentrations of several amino acids are altered in anemic rats (Lewis et al., 2001b). Further work is required to determine the environmental regulation of other amino acid transporters in the placenta that have been implicated in facilitating amino acid accumulation, exchange and efflux (Cleal and Lewis, 2008; Lager and Powell, 2012), as well as those carrier proteins implicated in ion transportation (Gallou-Kabani et al., 2010; Gabory et al., 2012). Thus, akin to glucose, the capacity of the placenta to 
transport amino acids is sensitive to changes in maternal nutrient and oxygen availability during pregnancy.

Although less studied compared to amino acid and glucose, the capacity of the placenta for fatty acid uptake and transfer to the fetus is also modified by the maternal environment. In mice and rats fed high-fat diets during pregnancy, the abundances of lipoprotein lipase, fatty acid binding protein, very low-density lipoprotein receptor and/or fatty acid transporter protein are increased in the placenta near term, depending on the content of fat in the diet and whether simple sugars were additionally consumed in excess (Rebholz et al., 2011; Qiao et al., 2012, 2015; Mazzucco et al., 2013; Sferruzzi-Perri et al., 2013; Reynolds et al., 2015). Moreover, placental uptake and fetal accumulation of maternally supplied triglycerides is increased in mice fed high-fat diets (Rebholz et al., 2011). Combined, these studies indicate that placental fatty acid transport capacity is enhanced by excess maternal dietary fat, and is consistent with the increased accumulation of fat within the fetus (Mazzucco et al., 2013; Qiao et al., 2015). Placental expression of genes involved in maternofetal lipid transfer is also increased in undernourished mice and may represent a compensatory attempt to maintain the fetal nutrient balance (Chen et al., 2013). However, further work is required to determine whether nutritional scarcity and reduced maternal oxygenation affects the lipid transport capabilities of the placenta. Moreover, the environmental regulation of materno-fetal nutrient transfer via the endocytosis-exocytosis pathway requires investigation. A need for this is reflected by observations indicating that substrate uptake via endocytosis is increased in trophectoderm cells and the yolk sac during early mouse development in response to maternal protein restriction (Watkins et al., 2008; Sun et al., 2014).

\section{REGULATION OF OTHER ESSENTIAL PLACENTAL FUNCTIONS BY THE MATERNAL ENVIRONMENT}

The placenta secretes hormones that modulate maternal adaptations to pregnancy, with consequences for resource allocation to the fetus. As mentioned previously, many of the environmental manipulations in mice, rats and guinea pigs affect the volume fraction and/or volume of the placental endocrine region, which will have implications for absolute endocrine output into the mother (Table 1). Furthermore, the expression of individual hormones including, prolactin-related genes, pregnancy-specific glycoproteins, angiotensinogen, appetite regulating peptides and cytokines, is also altered by maternal nutrition and/or the oxygen supply (Ain et al., 2004; Ho-Chen et al., 2006; Caminos et al., 2008; Rosario et al., 2008; Schulz et al., 2012; Chen et al., 2013; Mazzucco et al., 2013; Cuffe et al., 2014b; George et al., 2014; Wang et al., 2015). In addition, the ability of the placenta to act as a barrier to circulating maternal hormones as well as xenobiotics, is affected by the environment of the mother (Table 1). For instance, dietary manipulation and inhalation hypoxia in rodents changes the placental expression of enzymes like $11 \beta$-hydroxysteroid dehydrogenases type 1 and 2 that activate and inactivate circulating glucocorticoids, respectively, with implications for fetal growth and maturation (Lesage et al., 2001; Belkacemi et al., 2011a,b; Gao et al., 2012a,b, 2013; Vaughan et al., 2012b, 2013, 2015a,b; Cuffe et al., 2014a; Bellisario et al., 2015a,b). Moreover, both a high-fat diet in mice and undernutrition in guinea pigs diminishes the abundance and/or activity of protective transporter proteins in the placenta, including p-glycoprotein and other ATP-binding cassette $(\mathrm{ABC})$ drug efflux proteins which would have consequences for fetal exposure to endogenous and exogenous substances in the maternal circulation (Soo et al., 2012; Wang et al., 2015). Further work is required to elucidate the environmental regulation of alternate, essential placental functions in the context of fetal development and growth.

Thus, the maternal environment affects placental phenotype which has implications for the amount and relative proportions of specific metabolic substrates as well as growth-regulating hormones supplied to the fetus at different stages of development. Few studies have considered the implication of conceptus sex in context (Gallou-Kabani et al., 2010; Vickers et al., 2011; Gabory et al., 2012; King et al., 2013; Cuffe et al., 2014a; Reynolds et al., 2015; see Table 1). However, the interaction of conceptus sex with environmentally-induced changes in placental phenotype will be important for understanding the developmental programming of disease susceptibility beyond the womb.

\section{EFFECTS OF MATERNAL ENVIRONMENT ON OFFSPRING GROWTH}

Several of the environmental challenges reported to affect placental phenotype (Table 1) have been associated with both immediate and long-term effects on offspring growth and wellbeing into adulthood (Table 2). Numerous adverse prenatal environments alter postnatal growth, but the specific effect is dependent on the timing and severity of the insult, as well as on the quality of the postnatal environment to which the offspring is exposed. Prenatal perturbations, such as calorie restriction (10-35\%; Kind et al., 1999, 2002, 2003; Vickers et al., 2000; Riviere et al., 2005; Breton et al., 2009; Camm et al., 2011; Lukaszewski et al., 2011, 2013), low-protein diet (6\%; Sathishkumar et al., 2009, 2012, 2015), iron restriction (Crowe et al., 1995; Lewis et al., 2001c, 2002) and uterine artery ligation (e.g., Wlodek et al., 2007, 2008; Siebel et al., 2008) in rats and guinea pigs reduce birth weight. Furthermore, offspring remain smaller through to adulthood, irrespective of the stage at which the manipulation occurs prenatally. Interestingly, exposure to $50 \%$ calorie restriction can have variable effects on postnatal growth, depending on whether pups are cross-fostered onto ad libitum fed dams after birth. Cross-fostering offspring exposed to calorie restriction prenatally results in a significant period of catch-up growth, and an increase in body weight in adulthood (Desai et al., 2008; Magee et al., 2008; Khorram et al., 2011, 2015; Fukami et al., 2012). Conversely leaving calorie-restricted offspring with their mothers during lactation does not appear to increase postnatal body weight (Leonhardt et al., 2002, 2003; Sebaai et al., 2002a,b, 2004; Vieau et al., 2007; Delahaye et al., 2008, 2010; Coupe et al., 2009; Laborie et al., 2011; Wattez 


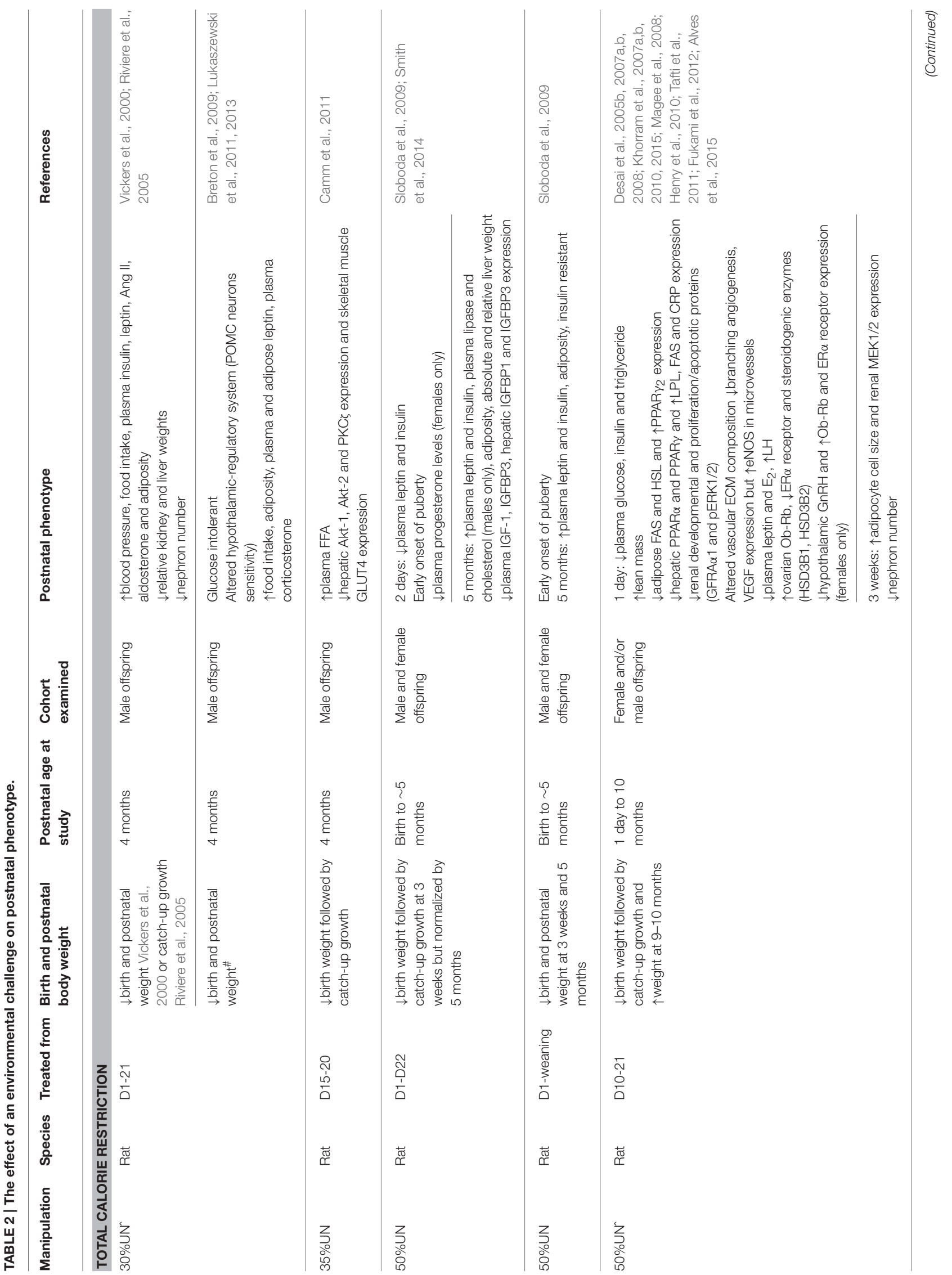




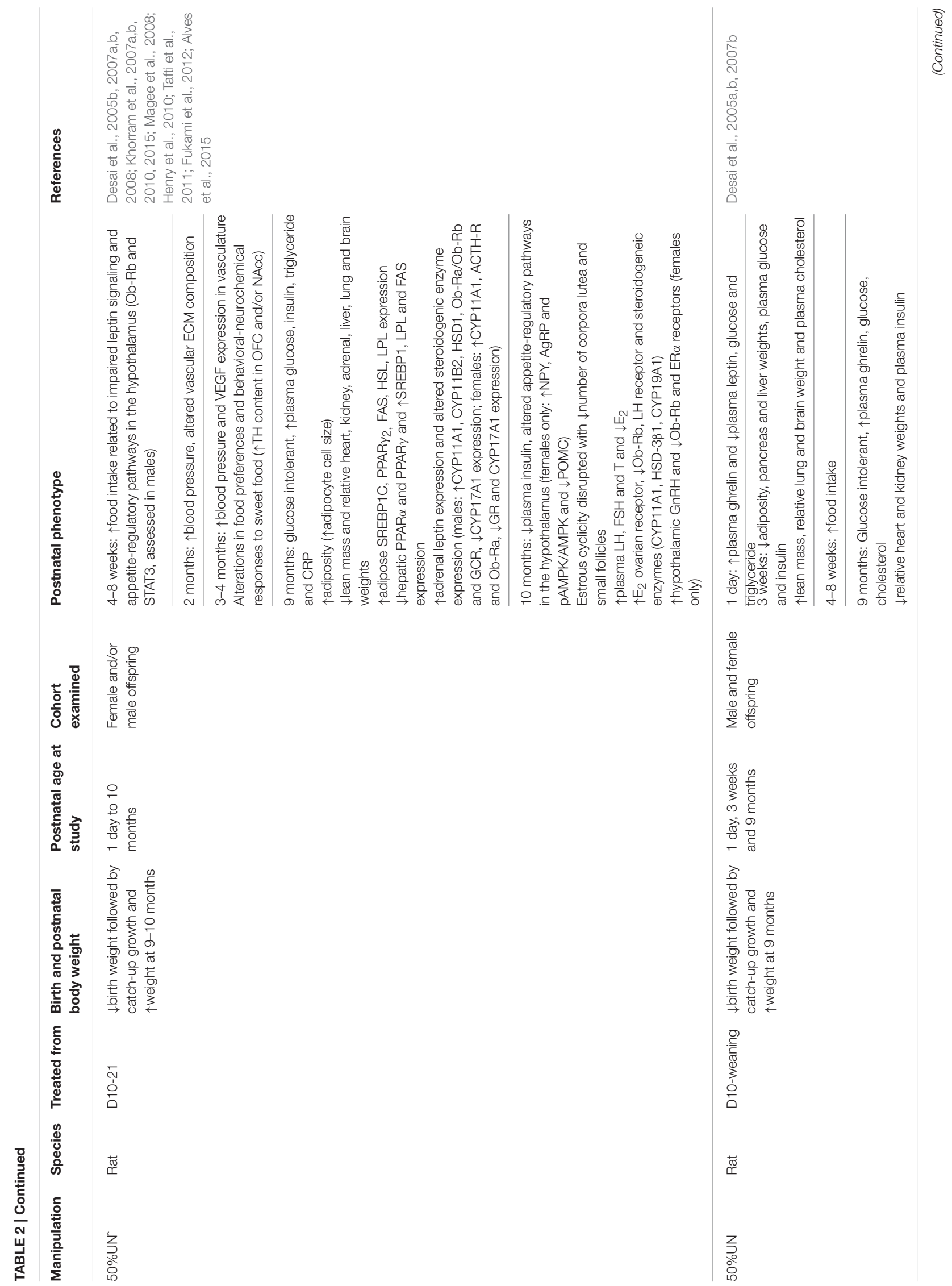




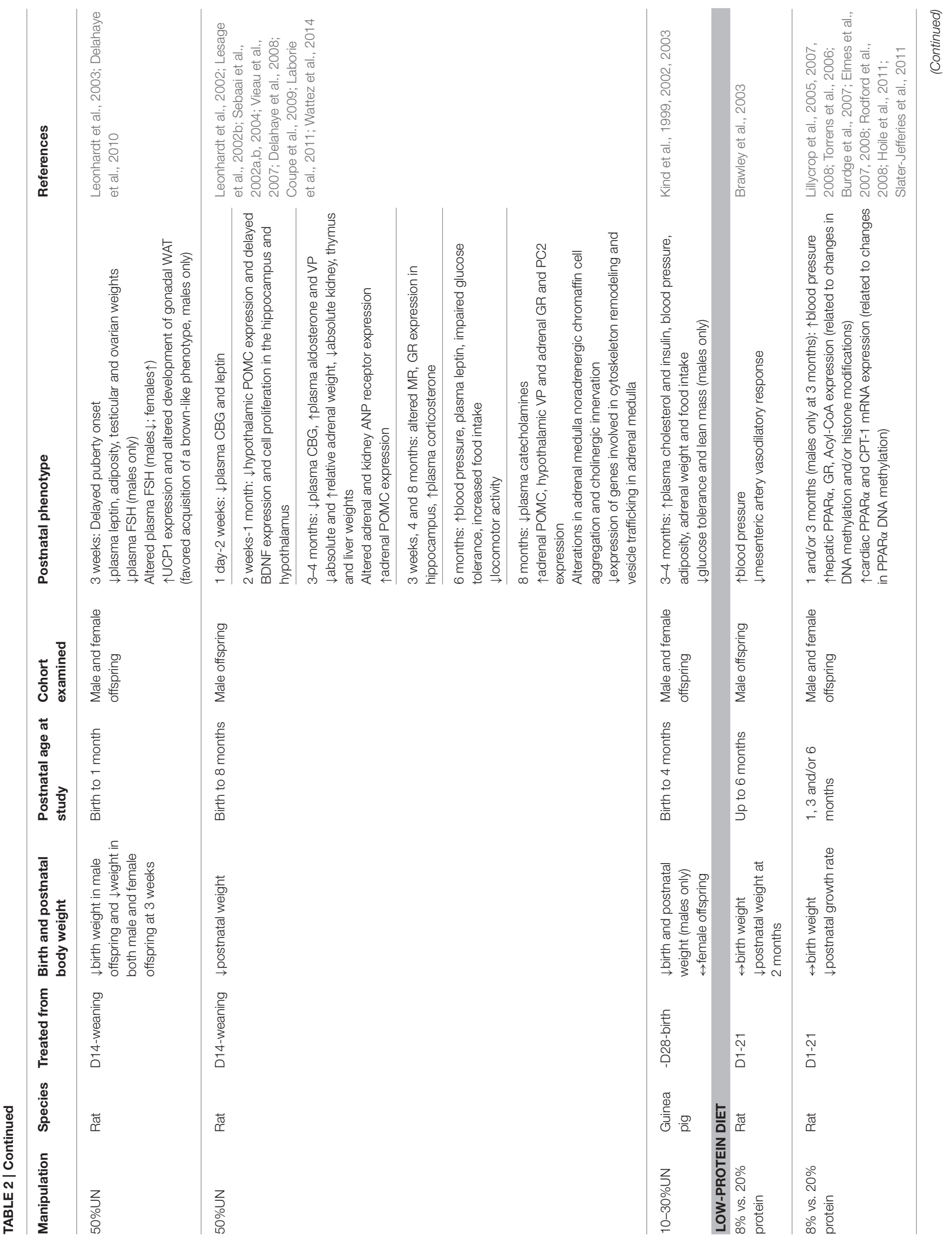




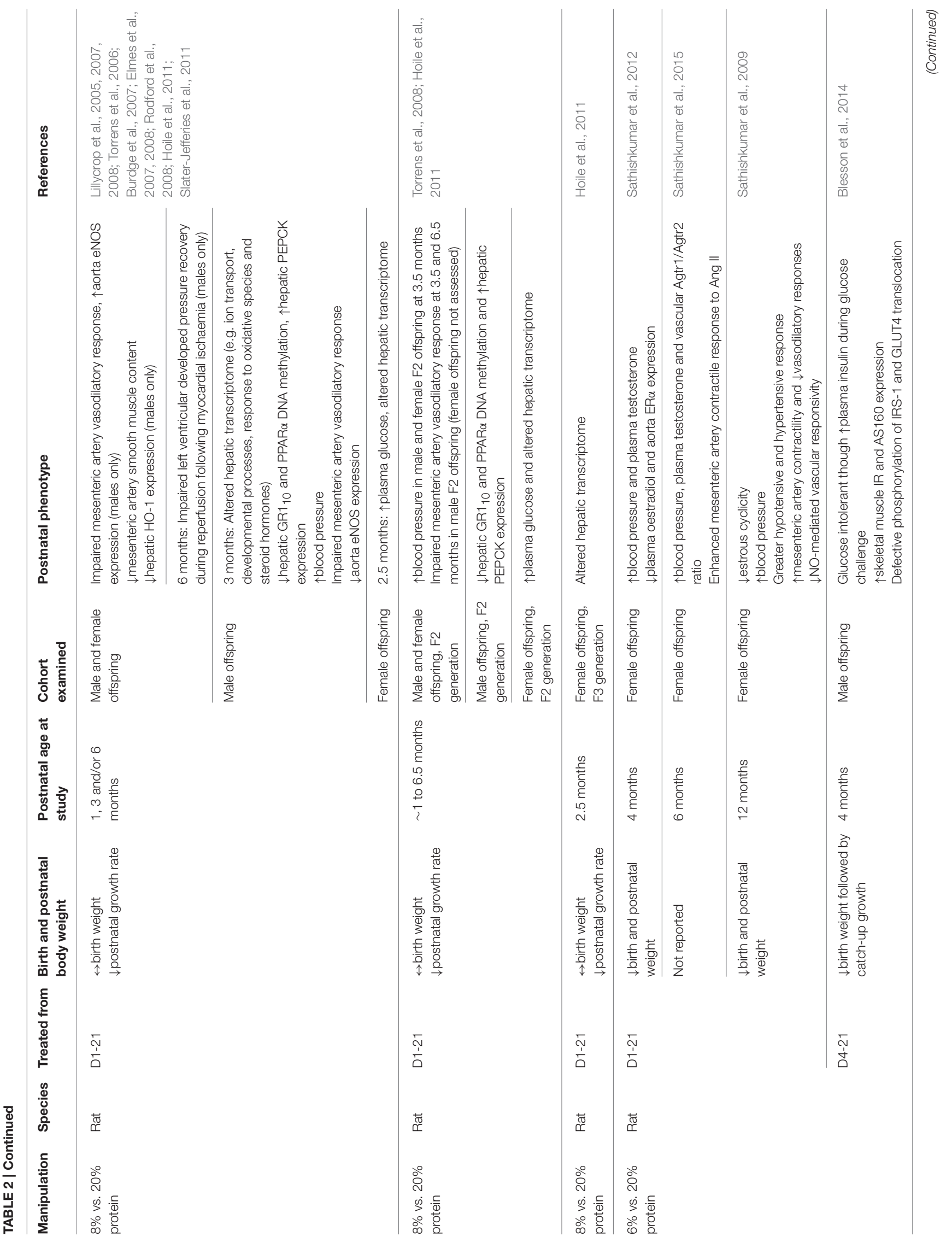




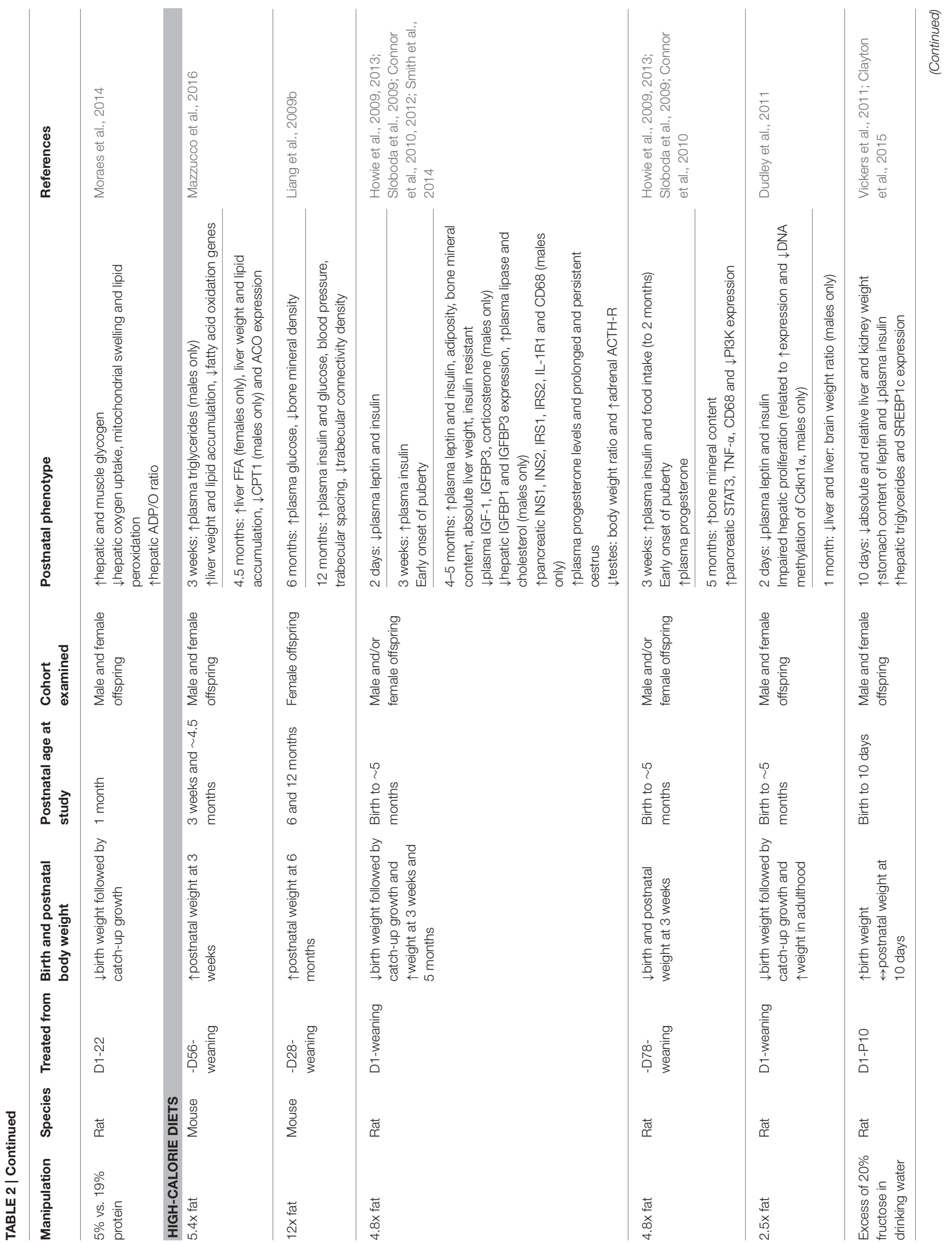




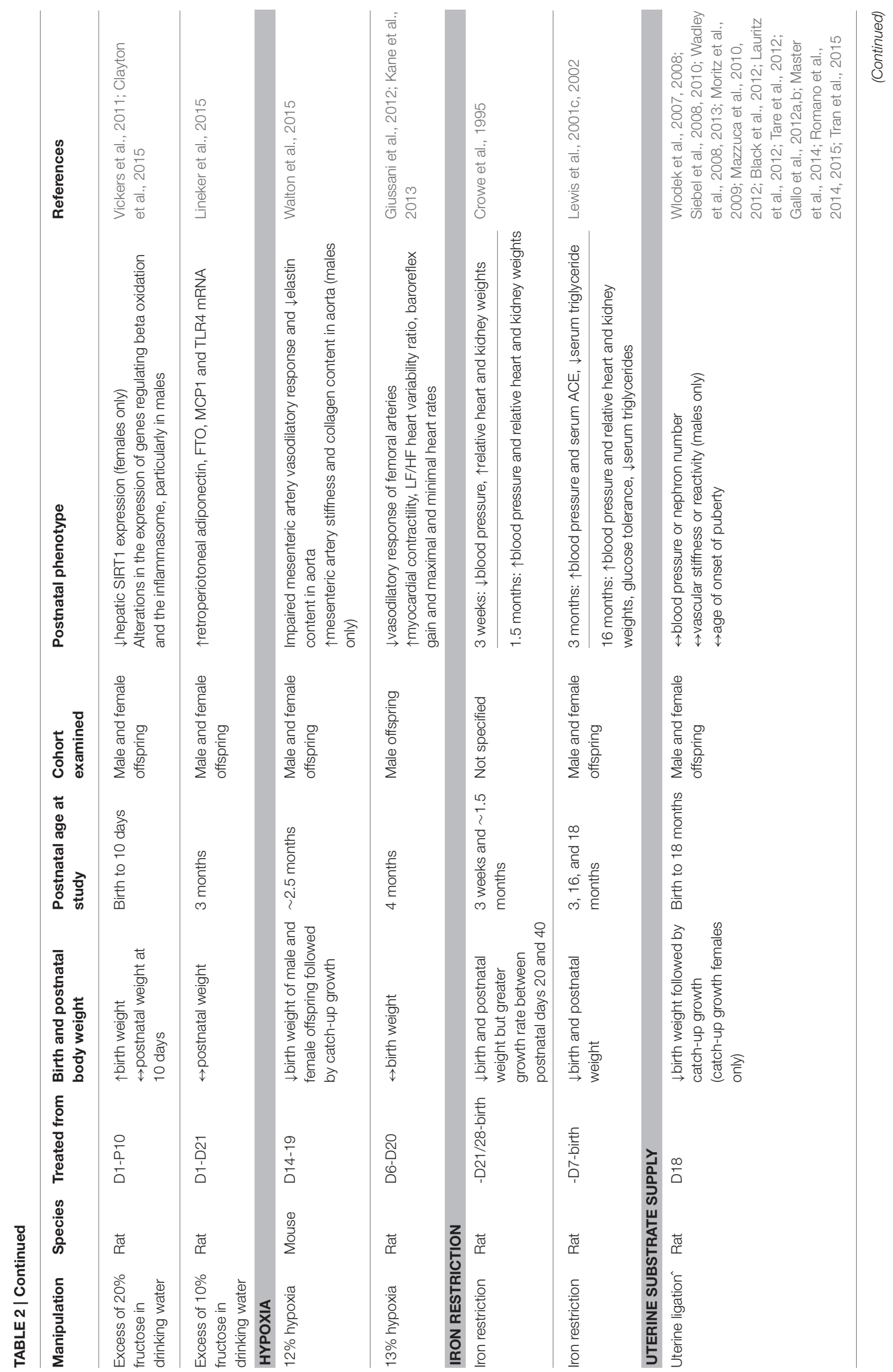




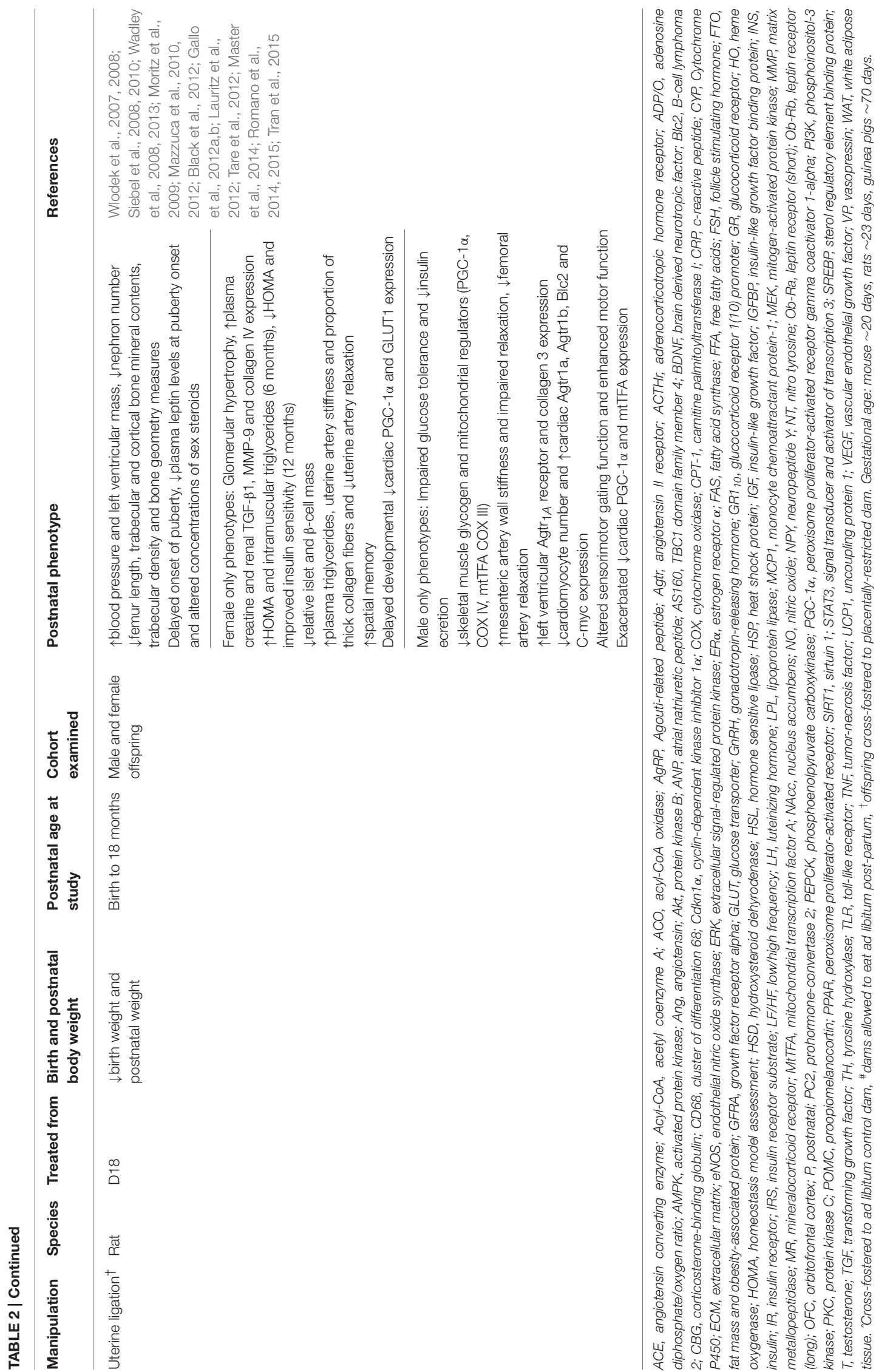




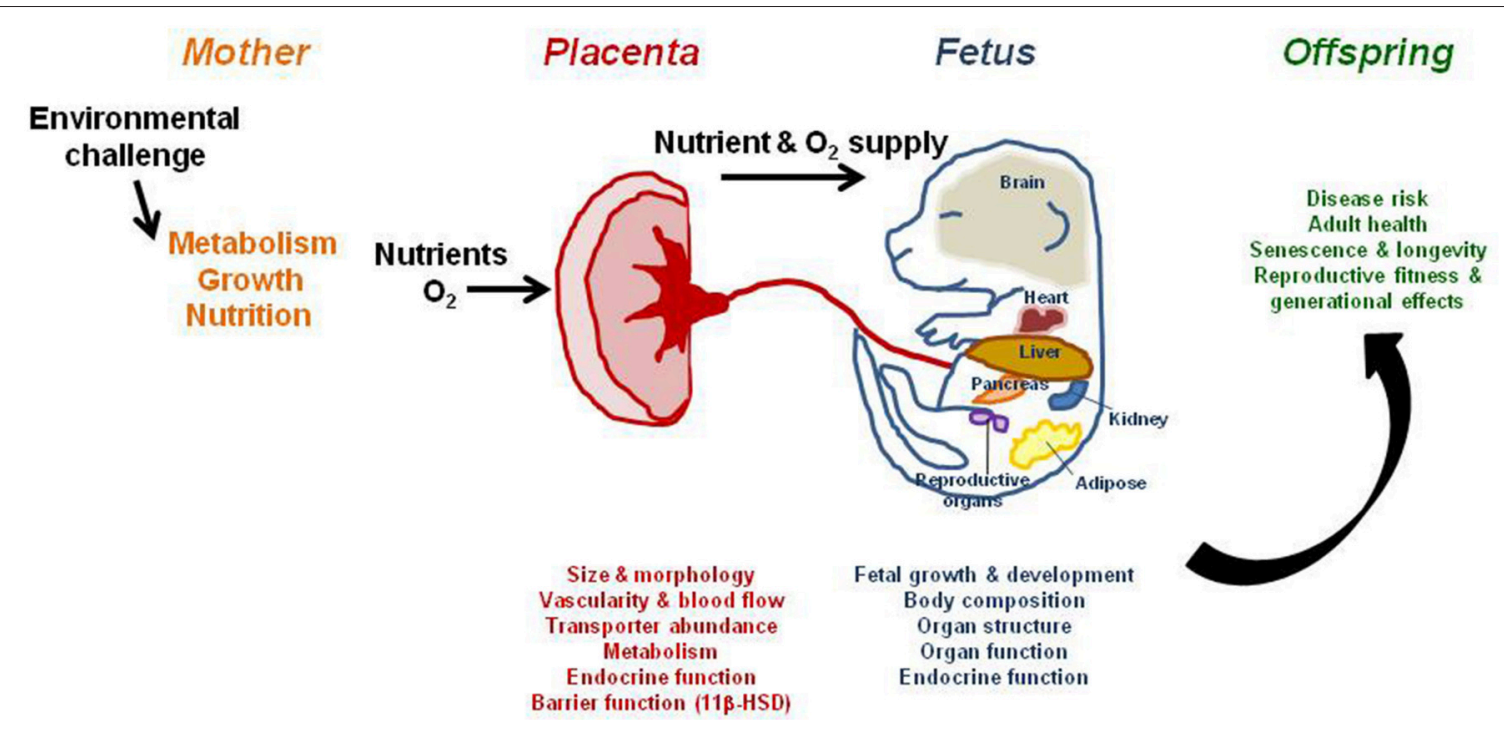

FIGURE 1 | The effect of an environmental challenge, such as maternal nutrient manipulation or oxygen scarcity, on placental phenotype, fetal growth, and offspring outcome. The placenta can adapt morphologically and functionally to optimize substrate supply and fetal growth in the face of an environmental challenge. While these adaptations may meet the fetal drive for growth, they alter the amount and relative proportions of specific metabolic substrates supplied to the fetus during development. This will ultimately program physiological systems at the gene, cell, tissue, organ, and system levels and cause permanent structural and functional changes, leading to overt disease in adulthood, particularly with increasing age.

et al., 2014), which may relate to impaired mammary function and compromised milk quality and quantity (Wlodek et al., 2005; O’Dowd et al., 2008). Hypoxia can reduce birth weight in rodents if exposure is during the latter third of pregnancy and is below $13 \%$ inspired oxygen, with body weight normalizing by adulthood (Walton et al., 2015). Gestational anemia induced by an iron-depleted maternal diet also reduces birth weight, with changes in postnatal growth rate depending on the length of maternal anemia prior to pregnancy (Crowe et al., 1995; Lewis et al., 2001c, 2002). Maternal high-fat diets often result in an increase in postnatal body weight at weaning and in adulthood, even when birth weight is decreased or unchanged, and may relate to whether the diet is continued during lactation (Howie et al., 2009, 2013; Liang et al., 2009b; Sloboda et al., 2009; Connor et al., 2010, 2012; Dudley et al., 2011; Smith et al., 2014; Mazzucco et al., 2016). In contrast, excess fructose may increase birth weight although postnatal growth of offspring may not be significantly altered and is normalized by adulthood (Vickers et al., 2011; Clayton et al., 2015; Lineker et al., 2015). Thus, alterations in the environment provided by the mother during pregnancy exert affects on offspring growth. Further work is required to determine the effect of calorie-dense diets and reduced maternal oxygen availability on mammary gland function in relation to offspring growth postnatally. Nonetheless, beyond gross weight, an environmental challenge to the mother in pregnancy and/or lactation effects the body composition of the offspring; that is the proportion of adipose versus lean mass and the absolute and relative weights of several individual organs (Desai et al., 2005b; Table 2). Alterations in offspring development and growth will have implications for whole body and organ function.

\section{EFFECTS OF MATERNAL ENVIRONMENT ON OFFSPRING CARDIOVASCULAR STRUCTURE AND FUNCTION}

Calorie restriction, low-protein diet, iron restriction and uterine artery ligation have all been shown to increase systolic blood pressure in adult offspring (Crowe et al., 1995; Vickers et al., 2000; Lewis et al., 2001c, 2002; Kind et al., 2002; Brawley et al., 2003; Riviere et al., 2005; Torrens et al., 2006, 2008; Elmes et al., 2007, 2008; Khorram et al., 2007a; Wlodek et al., 2008; Sathishkumar et al., 2009, 2012, 2015; Gallo et al., 2012b; Master et al., 2014; Wattez et al., 2014; Tran et al., 2015). The degree to which blood pressure is elevated can vary with the specific environmental exposure, and may be due, at least in part, to structural remodeling of offspring cardiac tissue (Crowe et al., 1995; Lewis et al., 2001c, 2002; Wlodek et al., 2008; Black et al., 2012) and blood vessels (Khorram et al., 2007b; Rodford et al., 2008; Giussani et al., 2012; Walton et al., 2015), changes in the expression of genes and miRNAs involved in cardiac energy metabolism (SlaterJefferies et al., 2011), extracellular matrix remodeling (Khorram et al., 2007a, 2010; Wlodek et al., 2008), cardiac hypertrophy (Black et al., 2012), and mitochondrial biogenesis (Wadley et al., 2013). Alterations in the reactivity of resistance arteries to vasodilators or constrictors and/or myocardium contractility, may also contribute to elevated blood pressure in adult offspring (Brawley et al., 2003; Torrens et al., 2006; Sathishkumar et al., 2009, 2015; Mazzuca et al., 2010, 2012; Giussani et al., 2012, 2014; Tare et al., 2012; Kane et al., 2013; Walton et al., 2015). In relation to high-calorie diets in which the placental phenotype has been characterized, only one study has reported 
elevated systolic blood pressure in adult offspring (Liang et al., 2009b).

Blood pressure assessments have predominately been performed in male offspring. Whilst some studies have assessed blood pressure in female offspring (Elmes et al., 2007, 2008; Khorram et al., 2007a; Liang et al., 2009b), they often present with less severe cardiovascular dysfunction than males. Modulation of the renin-angiotensinogen system by estrogen may confer protection against the programming effects of prenatal insults on cardiac regulatory systems in female offspring (Ojeda et al., 2007, 2014). Moreover, male fetuses may be more sensitive to altered nutrient and oxygen supply due to their higher rate of intrauterine growth, compared to females (Clifton, 2010).

\section{EFFECTS OF MATERNAL ENVIRONMENT ON OFFSPRING CEREBRAL STRUCTURE AND FUNCTION}

In the hypothalamus, leptin receptor (Ob-Rb)-stimulated signal transducer and activator of transcription (STAT)-3 signaling is crucial in the control of feeding by leptin (Ghilardi et al., 1996). Calorie restriction (50\%, day (D)10-21) has been shown to alter hypothalamic $\mathrm{Ob}-\mathrm{Rb}$ gene expression and STAT3 protein expression, in the early postnatal period (Desai et al., 2007a). In addition, calorie restriction is associated with altered food preferences in adulthood, dopamine sensitivity and expression of appetite-stimulatory factors and hypothalamic responsiveness to alterations in energy status (altered genes include: neuropeptide Y (NPY), Agouti-related peptide (AgRP), proopiomelanocortin (POMC), and activated protein kinase (AMPK; Delahaye et al., 2008; Fukami et al., 2012; Lukaszewski et al., 2013; Alves et al., 2015). Together, these findings suggest an enhanced appetite drive which is consistent with offspring hyperphagia reported in many of these models, thus contributing to the increased risk of adult obesity in offspring (Vickers et al., 2000; Kind et al., 2003; Desai et al., 2007a; Breton et al., 2009; Delahaye et al., 2010).

Calorie restriction (50\% of ad libitum) from day 14 through to weaning alters the structural development of the hypothalamus and hippocampus, by changing the production of brainderived neurotrophic factor (BDNF) and cell proliferation during development (Coupe et al., 2009). These early modifications in cerebral structure may have long-lasting consequences on the regulation of neuroendocrine activity, energy metabolism and cognition. Uterine artery ligation, resulting in low-birth weight offspring, impairs sensorimotor gating, but enhances motor function and spatial memory in adult offspring (Lauritz et al., 2012). These data are inconsistent with reports in the literature which supports the in utero programming of motor dysfunction (Smart et al., 1973) and altered exploratory behavior (Almeida et al., 1996) in low-birth weight offspring. Thus, further studies are required to verify the motor and cognitive deficit in offspring from an altered prenatal environment, where the placental phenotype is known (for instance in response to gestational hypoxia, protein deprivation or excess maternal calories).

\section{EFFECTS OF MATERNAL ENVIRONMENT ON OFFSPRING REPRODUCTIVE ORGANS STRUCTURE AND FUNCTION}

Calorie restriction (50\%, D10-21) increases ovarian expression of enzymes involved in androgen synthesis and plasma luteinizing hormone/follicle stimulating hormone (LH/FSH) concentrations, whilst reducing estrogen receptor $(\mathrm{ER} \alpha)$ abundance and the number of corpora lutea in prepubescent and adult female offspring (Khorram et al., 2015). Calorie restriction from day 14 of pregnancy through to weaning also has long-term consequences for the size and histology of the genitals and plasma gonadotropin levels (Leonhardt et al., 2003). Furthermore, the age of onset of puberty and estrous cyclicity is altered in offspring exposed to maternal calorie restriction (50\% UN; Leonhardt et al., 2003; Sloboda et al., 2009; Khorram et al., 2015), low-protein diet (Sathishkumar et al., 2009), high-fat diet (Sloboda et al., 2009; Connor et al., 2012), and uterine artery ligation (Romano et al., 2015). In part, these changes may be related to alterations in hypothalamic-gonadal communication, as hypothalamic gonadotropin-releasing hormone $(\mathrm{GnRH})$ production and estrogen receptor expression are altered in offspring exposed to gestational maternal calorie restriction (Khorram et al., 2015). These studies indicate that the prenatal environment can alter reproductive maturation and function, which may be associated with altered fertility, thereby impacting the health and reproductive potential of future generations.

\section{EFFECTS OF MATERNAL ENVIRONMENT ON OFFSPRING KIDNEY STRUCTURE AND FUNCTION}

Calorie restriction (30\% UN, D1-21 or $50 \%$ D10-21) results in a decreased nephron number in male offspring in the early postnatal period and in adulthood (Riviere et al., 2005; Henry et al., 2010). Uterine artery ligation also reduces nephron number in male and female offspring (Wlodek et al., 2008; Moritz et al., 2009), with female offspring developing compensatory glomerular hypertrophy and renal dysfunction later in life (Moritz et al., 2009). Dysregulated glial cell line-derived neurotrophic factor (GDNF) and mitogen-activated protein kinase-extracellular signal-regulated protein kinase (MAPKERK) signaling and increased apoptosis (Henry et al., 2010; Tafti et al., 2011), in conjunction with elevated vasopressin (Sebaai et al., 2002b), angiotensin II and aldosterone levels (Ang II; Riviere et al., 2005), may be key underlying factors in the pathogenesis of reduced offspring nephrogenesis and programmed hypertension.

\section{EFFECTS OF MATERNAL ENVIRONMENT ON OFFSPRING METABOLIC SYSTEMS}

The effects of an adverse prenatal environment on metabolic systems have been extensively studied in a variety of animal models. Many of the prenatal insults report impaired glucose tolerance and/or insulin sensitivity which relate to defects in 
pancreatic formation and insulin production as well as changes in the expression of proteins in insulin-responsive pathways in key metabolic tissues like the liver, skeletal muscle and adipose tissue (Table 2; Siebel et al., 2010; Camm et al., 2011; Gallo et al., 2012a; Tran et al., 2012; Howie et al., 2013; Blesson et al., 2014). Moreover, calorie restriction (30\% D1-12 or 50\% D1-21), lowprotein (16\% D1-21) and high-calorie diets (2.5-times fat D1weaning) result in hyperinsulinaemia, hyperglycaemia and/or hyperleptinaemia and increased adiposity in adult offspring (Vickers et al., 2000; Kind et al., 2003; Desai et al., 2005a, 2008; Magee et al., 2008; Breton et al., 2009; Howie et al., 2009, 2013; Lukaszewski et al., 2011; Fukami et al., 2012; Blesson et al., 2014). Furthermore, studies in these models have shown increases in hepatic triglycerides (Clayton et al., 2015; Mazzucco et al., 2016) and plasma cholesterol and triglycerides (Desai et al., 2007b, 2008; Magee et al., 2008; Smith et al., 2014). Maternal low-protein diets and uterine artery ligation also affect nutrient storage and metabolism in offspring tissues, including the liver and skeletal muscle (Wadley et al., 2008; Moraes et al., 2014). Persistent changes in hepatic (Magee et al., 2008; Clayton et al., 2015), adrenal (Khorram et al., 2011), and adipogenic (Desai et al., 2008) gene expression and DNA methylation (Lillycrop et al., 2005, 2007, 2008; Burdge et al., 2007; Dudley et al., 2011) have also been reported in these animal models, suggesting that epigenetic processes may be central to the mechanism by which the early environment can increase susceptibility to metabolic disease in later life (Lillycrop and Burdge, 2011). Increased adiposity of the fetus has been reported in guinea pig offspring following calorie restriction, which may contribute to the metabolic and cardiovascular dysfunction that these offspring develop as adults (Kind et al., 2005).

\section{EFFECTS OF MATERNAL ENVIRONMENT ON OTHER PHYSIOLOGICAL SYSTEMS}

The prenatal environment may also alter other physiological systems in the fetus, having long-term effects on the offspring (e.g., bone development; Romano et al., 2014; Anevska et al., 2015) and the hypothalamic-pituitary axis (Lesage et al., 2002b). However, the sensitivity of individual organs and tissues to a prenatal challenge will likely reflect the specific substrate demands of that organ and its tempo of development. Several experimental studies report that hypoxia during pregnancy decreases maternal food intake (Camm et al., 2010; Higgins et al., 2015), and likewise undernutrition in pregnancy has been reported to cause reductions in uterine blood flow which would also deprive the conceptus of oxygen (Ahokas et al., 1983). Thus, the impact of prenatal nutrition and oxygen availability are inter-related and will together determine the phenotype of the offspring. Furthermore, the interaction of the pre-and

\section{REFERENCES}

Ahokas, R. A., Anderson, G. D., and Lipshitz, J. (1983). Effect of dietary restriction, during the last week only or throughout gestation, on cardiac output and uteroplacental blood flow in pregnant rats. J. Nutr. 113, 1766-1776. postnatal environments is also important in determining the specific postnatal profile of the offspring. Cross-fostering pups after birth, thereby altering the lactational environment (Wlodek et al., 2005; O'Dowd et al., 2008), or varying the diet after weaning (e.g., Howie et al., 2009; Connor et al., 2010, 2012), exposes the offspring to a "second hit" and may exacerbate the effects of an adverse prenatal challenge on the phenotype of the offspring. Poor maternal care and bonding may also impact the early postweaning phenotype of the offspring, contributing to later life physiology and disease risk (Connor et al., 2012). The postnatal environment therefore needs to be considered when reviewing the phenotypic changes observed in adult offspring. Clearly the maternal environment can impact offspring metabolism and health, though emerging evidence suggests that offspring may also prematurely age (with altered expression of senescence markers; Tarry-Adkins et al., 2009) and programming effects may extend to subsequent generations (e.g., Burdge et al., 2007; Hoile et al., 2011).

\section{SUMMARY}

The maternal environment clearly affects placental and fetal growth and the postnatal phenotype of offspring (Figure 1). Identifying the postnatal functional consequences arising from an adverse prenatal environment with a known placental phenotype could aid in the development of placental biomarkers for early diagnosis, assist in identifying susceptible individuals at risk for adult disease, and contribute to the discovery of novel therapeutic strategies to prevent or ameliorate programmed effects. Indeed, placental phenotypic traits have been associated with various diseases in humans postnatally, including insulin resistance, hypertension, heart disease, asthma, cancers, as well as premature death (Barker et al., 1993, 2010a,b,c, 2011, 2012, 2013a,b,c; van Abeelen et al., 2011).

\section{AUTHOR CONTRIBUTIONS}

ANS and EJC contributed equally to reviewing the literature and writing and editing the manuscript.

\section{FUNDING}

ANS is supported by a Royal Society Dorothy Hodgkin Fellowship.

\section{ACKNOWLEDGMENTS}

The authors would like to thank Professor Graham Burton for editorial advice on the manuscript.

Ahokas, R. A., Lahaye, E. B., Anderson, G. D., and Lipshitz, J. (1981). Effect of maternal dietary restriction on fetal growth and placental transfer of alphaamino isobutyric acid in rats. J. Nutr. 111, 2052-2058.

Ain, R., Dai, G., Dunmore, J. H., Godwin, A. R., and Soares, M. J. (2004). A prolactin family paralog regulates reproductive adaptations to a 
physiological stressor. Proc. Natl. Acad. Sci. USA. 101, 16543-16548. doi: 10.1073/pnas.0406185101

Alam, S. M., Konno, T., Dai, G., Lu, L., Wang, D., Dunmore, J. H., et al. (2007). A uterine decidual cell cytokine ensures pregnancy-dependent adaptations to a physiological stressor. Development 134, 407-415. doi: 10.1242/dev. 02743

Alexander, B. T., Kassab, S. E., Miller, M. T., Abram, S. R., Reckelhoff, J. F., Bennett, W. A., et al. (2001). Reduced uterine perfusion pressure during pregnancy in the rat is associated with increases in arterial pressure and changes in renal nitric oxide. Hypertension 37, 1191-1195. doi: 10.1161/01.HYP.37.4.1191

Almeida, S. S., Tonkiss, J., and Galler, J. R. (1996). Prenatal protein malnutrition affects exploratory behavior of female rats in the elevated plus-maze test. Physiol. Behav. 60, 675-680. doi: 10.1016/S0031-9384(96)80047-3

Alves, M. B., Dalle Molle, R., Desai, M., Ross, M. G., and Silveira, P. P. (2015). Increased palatable food intake and response to food cues in intrauterine growth-restricted rats are related to tyrosine hydroxylase content in the orbitofrontal cortex and nucleus accumbens. Behav. Brain Res. 287, 73-81. doi: 10.1016/j.bbr.2015.03.019

Alzamendi, A., Del Zotto, H., Castrogiovanni, D., Romero, J., Giovambattista, A., and Spinedi, E. (2012). Oral metformin treatment prevents enhanced insulin demand and placental dysfunction in the pregnant rat fed a fructose-rich diet. ISRN Endocrinol. 2012, 757913. doi: 10.5402/2012/757913

Anevska, K., Gallo, L. A., Tran, M., Jefferies, A. J., Wark, J. D., Wlodek, M. E., et al. (2015). Pregnant growth restricted female rats have bone gains during late gestation which contributes to second generation adolescent and adult offspring having normal bone health. Bone 74, 199-207. doi: 10.1016/j.bone.2015.01.018

Armitage, J. A., Khan, I. Y., Taylor, P. D., Nathanielsz, P. W., and Poston, L. (2004). Developmental programming of the metabolic syndrome by maternal nutritional imbalance: how strong is the evidence from experimental models in mammals? J. Physiol. 561, 355-377. doi: 10.1113/jphysiol.2004.072009

Bacon, B. J., Gilbert, R. D., Kaufmann, P., Smith, A. D., Trevino, F. T., and Longo, L. D. (1984). Placental anatomy and diffusing capacity in guinea pigs following long-term maternal hypoxia. Placenta 5, 475-487. doi: 10.1016/S0143-4004(84)80002-8

Barker, D. J. (2004a). The developmental origins of adult disease. J. Am. Coll. Nutr. 23, 588S-595S. doi: 10.1080/07315724.2004.10719428

Barker, D. J. (2004b). The developmental origins of well-being. Philos. Trans. $R$. Soc. Lond. B Biol. Sci. 359, 1359-1366. doi: 10.1098/rstb.2004.1518

Barker, D. J. (2004c). Developmental origins of adult health and disease. J. Epidemiol. Comm. Health 58, 114-115. doi: 10.1136/jech.58.2.114

Barker, D. J., Gelow, J., Thornburg, K., Osmond, C., Kajantie, E., and Eriksson, J. G. (2010b). The early origins of chronic heart failure: impaired placental growth and initiation of insulin resistance in childhood. Eur. J. Heart Fail. 12, 819-825. doi: 10.1093/eurjhf/hfq069

Barker, D. J., Hales, C. N., Fall, C. H., Osmond, C., Phipps, K., and Clark, P. M. (1993). Type 2 (non-insulin-dependent) diabetes mellitus, hypertension and hyperlipidaemia (syndrome X): relation to reduced fetal growth. Diabetologia 36, 62-67. doi: 10.1007/BF00399095

Barker, D. J., Larsen, G., Osmond, C., Thornburg, K. L., Kajantie, E., and Eriksson, J. G. (2012). The placental origins of sudden cardiac death. Int. J. Epidemiol. 41, 1394-1399. doi: 10.1093/ije/dys116

Barker, D. J., and Osmond, C. (1986). Infant mortality, childhood nutrition, and ischaemic heart disease in England and Wales. Lancet 1, 1077-1081. doi: 10.1016/S0140-6736(86)91340-1

Barker, D. J., Osmond, C., Forsen, T. J., Thornburg, K. L., Kajantie, E., and Eriksson, J. G. (2013c). Foetal and childhood growth and asthma in adult life. Acta Paediatr. 102, 732-738. doi: 10.1111/apa.12257

Barker, D. J., Osmond, C., Thornburg, K. L., Kajantie, E., and Eriksson, J. G. (2011). The lifespan of men and the shape of their placental surface at birth. Placenta 32, 783-787. doi: 10.1016/j.placenta.2011.07.031

Barker, D. J., Osmond, C., Thornburg, K. L., Kajantie, E., and Eriksson, J. G. (2013a). The shape of the placental surface at birth and colorectal cancer in later life. Am. J. Hum. Biol. 25, 566-568. doi: 10.1002/ajhb.22409

Barker, D. J., Osmond, C., Thornburg, K. L., Kajantie, E., and Eriksson, J. G. (2013b). The intrauterine origins of Hodgkin's lymphoma. Cancer Epidemiol. 37, 321-323. doi: 10.1016/j.canep.2013.01.004
Barker, D. J., Thornburg, K. L., Osmond, C., Kajantie, E., and Eriksson, J. G. (2010a). The surface area of the placenta and hypertension in the offspring in later life. Int. J. Dev. Biol. 54, 525-530. doi: 10.1387/ijdb.082760db

Barker, D. J., Thornburg, K. L., Osmond, C., Kajantie, E., and Eriksson, J. G. (2010c). The prenatal origins of lung cancer. II. The placenta. Am. J. Hum. Biol. 22, 512-516. doi: 10.1002/ajhb.21041

Barker, D. J., Winter, P. D., Osmond, C., Margetts, B., and Simmonds, S. J. (1989). Weight in infancy and death from ischaemic heart disease. Lancet 2, 577-580. doi: 10.1016/S0140-6736(89)90710-1

Belkacemi, L., Desai, M., Nelson, D. M., and Ross, M. G. (2011b). Altered mitochondrial apoptotic pathway in placentas from undernourished rat gestations. Am. J. Physiol. Regul. Integr. Comp. Physiol. 301, R1599-R1615. doi: 10.1152/ajpregu.00100.2011

Belkacemi, L., Jelks, A., Chen, C. H., Ross, M. G., and Desai, M. (2011a). Altered placental development in undernourished rats: role of maternal glucocorticoids. Reprod. Biol. Endocrinol. 9, 105. doi: 10.1186/1477-7827-9-105

Bellisario, V., Panetta, P., Balsevich, G., Baumann, V., Noble, J., Raggi, C., et al. (2015a). Maternal high-fat diet acts as a stressor increasing maternal glucocorticoids' signaling to the fetus and disrupting maternal behavior and brain activation in C57BL/6J mice. Psychoneuroendocrinology 60, 138-150. doi: 10.1016/j.psyneuen.2015.06.012

Bellisario, V., Panetta, P., Balsevich, G., Baumann, V., Noble, J., Raggi, C., et al. (2015b). High-fat diet during pregnancy acts as a stressor increasing maternal glucocorticoids' signaling to the fetus and disrupting maternal behavior in a mouse model. Psychoneuroendocrinology 61, 10-10. doi: 10.1016/j.psyneuen.2015.07.414

Black, M. J., Siebel, A. L., Gezmish, O., Moritz, K. M., and Wlodek, M. E. (2012). Normal lactational environment restores cardiomyocyte number after uteroplacental insufficiency: implications for the preterm neonate. Am. J. Physiol. Regul. Integr. Comp. Physiol. 302, R1101-R1110. doi: 10.1152/ajpregu.00030.2012

Blesson, C. S., Sathishkumar, K., Chinnathambi, V., and Yallampalli, C. (2014). Gestational protein restriction impairs insulin-regulated glucose transport mechanisms in gastrocnemius muscles of adult male offspring. Endocrinology 155, 3036-3046. doi: 10.1210/en.2014-1094

Brawley, L., Itoh, S., Torrens, C., Barker, A., Bertram, C., Poston, L., et al. (2003). Dietary protein restriction in pregnancy induces hypertension and vascular defects in rat male offspring. Pediatr. Res. 54, 83-90. doi: 10.1203/01.PDR.0000065731.00639.02

Breton, C., Lukaszewski, M. A., Risold, P. Y., Enache, M., Guillemot, J., Riviere, G., et al. (2009). Maternal prenatal undernutrition alters the response of POMC neurons to energy status variation in adult male rat offspring. Am. J. Physiol. Endocrinol. Metab. 296, E462-E472. doi: 10.1152/ajpendo.90740.2008

Burdge, G. C., Slater-Jefferies, J., Torrens, C., Phillips, E. S., Hanson, M. A., and Lillycrop, K. A. (2007). Dietary protein restriction of pregnant rats in the F0 generation induces altered methylation of hepatic gene promoters in the adult male offspring in the F1 and F2 generations. Br. J. Nutr. 97, 435-439. doi: 10.1017/S0007114507352392

Caminos, J. E., Bravo, S. B., Gonzalez, C. R., Garces, M. F., Cepeda, L. A., Gonzalez, A. C., et al. (2008). Food-intake-regulating-neuropeptides are expressed and regulated through pregnancy and following food restriction in rat placenta. Reprod. Biol. Endocrinol. 6, 14. doi: 10.1186/1477-7827-6-14

Camm, E. J., Hansell, J. A., Kane, A. D., Herrera, E. A., Lewis, C., Wong, S., et al. (2010). Partial contributions of developmental hypoxia and undernutrition to prenatal alterations in somatic growth and cardiovascular structure and function. Am. J. Obstet. Gynecol. 203, 495.e24-495.e34. doi: 10.1016/j.ajog.2010.06.046

Camm, E. J., Martin-Gronert, M. S., Wright, N. L., Hansell, J. A., Ozanne, S. E., and Giussani, D. A. (2011). Prenatal hypoxia independent of undernutrition promotes molecular markers of insulin resistance in adult offspring. FASEB J. 25, 420-427. doi: 10.1096/fj.10-158188

Carter, A. M., Kingston, M. J., Han, K. K., Mazzuca, D. M., Nygard, K., and Han, V. K. (2005). Altered expression of IGFs and IGF-binding proteins during intrauterine growth restriction in guinea pigs. J. Endocrinol. 184, 179-189. doi: $10.1677 /$ joe.1.05781

Chakraborty, D., Rumi, M. A., Konno, T., and Soares, M. J. (2011). Natural killer cells direct hemochorial placentation by regulating hypoxia-inducible factor 
dependent trophoblast lineage decisions. Proc. Natl. Acad. Sci. U.S.A. 108, 16295-16300. doi: 10.1073/pnas.1109478108

Chen, P. Y., Ganguly, A., Rubbi, L., Orozco, L. D., Morselli, M., Ashraf, D., et al. (2013). Intrauterine calorie restriction affects placental DNA methylation and gene expression. Physiol. Genomics 45, 565-576. doi: 10.1152/physiolgenomics.00034.2013

Clayton, Z. E., Vickers, M. H., Bernal, A., Yap, C., and Sloboda, D. M. (2015). Early life exposure to fructose alters maternal, fetal and neonatal hepatic gene expression and leads to sex-dependent changes in lipid metabolism in rat offspring. PLOS ONE 10:e0141962. doi: 10.1371/journal.pone.0141962

Cleal, J., and Lewis, R. (2008). The Mechanisms and Regulation of Placental Amino Acid Transport to the Human Foetus. J. Neuroendocrinol. 20, 419-426. doi: 10.1111/j.1365-2826.2008.01662.x

Clifton, V. L. (2010). Review: sex and the human placenta: mediating differential strategies of fetal growth and survival. Placenta 31(Suppl.), S33-S39. doi: 10.1016/j.placenta.2009.11.010

Coan, P. M., Vaughan, O. R., McCarthy, J., Mactier, C., Burton, G. J., Constancia, M., et al. (2011). Dietary composition programmes placental phenotype in mice. J. Physiol. 589, 3659-3670. doi: 10.1113/jphysiol.2011.208629

Coan, P. M., Vaughan, O. R., Sekita, Y., Finn, S. L., Constancia, M., Burton, G. J., et al. (2010). Adaptations in placental phenotype support fetal growth during undernutrition of pregnant mice. J. Physiol. 588, 527-538. doi: 10.1113/jphysiol.2009.181214

Connor, K. L., Vickers, M. H., Beltrand, J., Meaney, M. J., and Sloboda, D. M. (2012). Nature, nurture or nutrition? Impact of maternal nutrition on maternal care, offspring development and reproductive function. J. Physiol. 590, 2167-2180. doi: 10.1113/jphysiol.2011.223305

Connor, K. L., Vickers, M. H., Cupido, C., Sirimanne, E., and Sloboda, D. M. (2010). Maternal high fat diet during critical windows of development alters adrenal cortical and medullary enzyme expression in adult male rat offspring. J. Dev. Orig. Health Dis. 1, 245-254. doi: 10.1017/S2040174410000346

Coupe, B., Dutriez-Casteloot, I., Breton, C., Lefevre, F., Mairesse, J., DickesCoopman, A., et al. (2009). Perinatal undernutrition modifies cell proliferation and brain-derived neurotrophic factor levels during critical time-windows for hypothalamic and hippocampal development in the male rat. J. Neuroendocrinol. 21, 40-48. doi: 10.1111/j.1365-2826.2008.01806.x

Cramer, S., Beveridge, M., Kilberg, M., and Novak, D. (2002). Physiological importance of system A-mediated amino acid transport to rat fetal development. Am. J. Physiol. Cell Physiol. 282, C153-C160.

Crowe, C., Dandekar, P., Fox, M., Dhingra, K., Bennet, L., and Hanson, M. A. (1995). The effects of anaemia on heart, placenta and body weight, and blood pressure in fetal and neonatal rats. J. Physiol. 488 (Pt 2), 515-519. doi: 10.1113/jphysiol.1995.sp020986

Cuffe, J. S., Walton, S. L., Singh, R. R., Spiers, J. G., Bielefeldt-Ohmann, H., Wilkinson, L., et al. (2014a). Mid- to late term hypoxia in the mouse alters placental morphology, glucocorticoid regulatory pathways and nutrient transporters in a sex-specific manner. J. Physiol. 592, 3127-3141. doi: 10.1113/jphysiol.2014.272856

Cuffe, J. S., Walton, S. L., Steane, S. E., Singh, R. R., Simmons, D. G., and Moritz, K. M. (2014b). The effects of gestational age and maternal hypoxia on the placental renin angiotensin system in the mouse. Placenta 35, 953-961. doi: 10.1016/j.placenta.2014.09.004

Dahlhoff, M., Pfister, S., Blutke, A., Rozman, J., Klingenspor, M., Deutsch, M. J., et al. (2014). Peri-conceptional obesogenic exposure induces sex-specific programming of disease susceptibilities in adult mouse offspring. Biochim. Biophys. Acta 1842, 304-317. doi: 10.1016/j.bbadis.2013.11.021

Das, U. G., Sadiq, H. F., Soares, M. J., Hay, W. W. Jr., and Devaskar, S. U. (1998). Time-dependent physiological regulation of rodent and ovine placental glucose transporter (GLUT-1) protein. Am. J. Physiol. 274, R339-R347.

Delahaye, F., Breton, C., Risold, P. Y., Enache, M., Dutriez-Casteloot, I., Laborie, C., et al. (2008). Maternal perinatal undernutrition drastically reduces postnatal leptin surge and affects the development of arcuate nucleus proopiomelanocortin neurons in neonatal male rat pups. Endocrinology 149, 470-475. doi: 10.1210/en.2007-1263

Delahaye, F., Lukaszewski, M. A., Wattez, J. S., Cisse, O., Dutriez-Casteloot, I., Fajardy, I., et al. (2010). Maternal perinatal undernutrition programs a "brownlike" phenotype of gonadal white fat in male rat at weaning. Am. J. Physiol. Regul. Integr. Comp. Physiol. 299, R101-R110. doi: 10.1152/ajpregu.00604.2009 de Rooij, S. R., Wouters, H., Yonker, J. E., Painter, R. C., and Roseboom, T. J. (2010). Prenatal undernutrition and cognitive function in late adulthood. Proc. Natl. Acad. Sci. U.S.A. 107, 16881-16886. doi: 10.1073/pnas.1009459107

Desai, M., Gayle, D., Babu, J., and Ross, M. G. (2005a). Programmed obesity in intrauterine growth-restricted newborns: modulation by newborn nutrition. Am. J. Physiol. Regul. Integr. Comp. Physiol. 288, R91-R96. doi: 10.1152/ajpregu.00340.2004

Desai, M., Gayle, D., Babu, J., and Ross, M. G. (2005b). Permanent reduction in heart and kidney organ growth in offspring of undernourished rat dams. Am. J. Obstet. Gynecol. 193, 1224-1232. doi: 10.1016/j.ajog.2005.05.041

Desai, M., Gayle, D., Babu, J., and Ross, M. G. (2007b). The timing of nutrient restriction during rat pregnancy/lactation alters metabolic syndrome phenotype. Am. J. Obstet. Gynecol. 196, 555e1-7. doi: 10.1016/j.ajog.2006.11.036

Desai, M., Gayle, D., Han, G., and Ross, M. G. (2007a). Programmed hyperphagia due to reduced anorexigenic mechanisms in intrauterine growth-restricted offspring. Reproductive sciences 14, 329-337. doi: 10.1177/1933719107303983

Desai, M., Guang, H., Ferelli, M., Kallichanda, N., and Lane, R. H. (2008). Programmed upregulation of adipogenic transcription factors in intrauterine growth-restricted offspring. Reprod. Sci. 15, 785-796. doi: $10.1177 / 1933719108318597$

Doherty, C. B., Lewis, R. M., Sharkey, A., and Burton, G. J. (2003). Placental composition and surface area but not vascularization are altered by maternal protein restriction in the rat. Placenta 24, 34-38. doi: 10.1053/plac.2002.0858

Dudley, K. J., Sloboda, D. M., Connor, K. L., Beltrand, J., and Vickers, M. H. (2011). Offspring of mothers fed a high fat diet display hepatic cell cycle inhibition and associated changes in gene expression and DNA methylation. PLoS ONE 6:e21662. doi: 10.1371/journal.pone.0021662

Duttaroy, A. K. (2009). Transport of fatty acids across the human placenta: a review. Prog. Lipid Res. 48, 52-61. doi: 10.1016/j.plipres.2008.11.001

Elmes, M. J., Gardner, D. S., and Langley-Evans, S. (2007). C., Fetal exposure to a maternal low-protein diet is associated with altered left ventricular pressure response to ischaemia-reperfusion injury. Br. J. Nutr. 98, 93-100. doi: 10.1017/S000711450769182X

Elmes, M. J., McMullen, S., Gardner, D. S., and Langley-Evans, S. C. (2008). Prenatal diet determines susceptibility to cardiac ischaemia-reperfusion injury following treatment with diethylmaleic acid and $\mathrm{N}$-acetylcysteine. Life Sci. 82, 149-155. doi: 10.1016/j.lfs.2007.10.022

Fowden, A. L., Forhead, A. J., Coan, P. M., and Burton, G. J. (2008). The placenta and intrauterine programming. J. Neuroendocrinol. 20, 439-450. doi: 10.1111/j.1365-2826.2008.01663.x

Fowden, A. L., and Moore, T. (2012). Maternal-fetal resource allocation: co-operation and conflict. Placenta 33(Suppl. 2), e11-e15. doi: 10.1016/j.placenta.2012.05.002

Fowden, A. L., Sferruzzi-Perri, A. N., Coan, P. M., Constancia, M., and Burton, G. J. (2009). Placental efficiency and adaptation: endocrine regulation. J. Physiol. 587, 3459-3472. doi: 10.1113/jphysiol.2009.173013

Fowden, A. L., Ward, J. W., Wooding, F. P., Forhead, A. J., and Constancia, M. (2006). Programming placental nutrient transport capacity. J. Physiol. 572, 5-15. doi: 10.1113/jphysiol.2005.104141

Franko, K. L., Forhead, A. J., and Fowden, A. L. (2009). Effects of maternal dietary manipulation during different periods of pregnancy on hepatic glucogenic capacity in fetal and pregnant rats near term. Nutr. Metab. Cardiovasc. Dis. 19, 555-562. doi: 10.1016/j.numecd.2008.11.001

Fukami, T., Sun, X., Li, T., Desai, M., and Ross, M. G. (2012). Mechanism of programmed obesity in intrauterine fetal growth restricted offspring: paradoxically enhanced appetite stimulation in fed and fasting states. Reprod. Sci. 19, 423-430. doi: 10.1177/1933719111424448

Gabory, A., Ferry, L., Fajardy, I., Jouneau, L., Gothie, J. D., Vige, A., et al. (2012). Maternal diets trigger sex-specific divergent trajectories of gene expression and epigenetic systems in mouse placenta. PLoS ONE 7:e47986. doi: 10.1371/journal.pone.0047986

Gaccioli, F., White, V., Capobianco, E., Powell, T. L., Jawerbaum, A., and Jansson, T. (2013). Maternal overweight induced by a diet with high content of saturated fat activates placental mTOR and eIF2alpha signaling and increases fetal growth in rats. Biol. Reprod. 89, 96. doi: 10.1095/biolreprod.113.109702

Gallo, L. A., Tran, M., Moritz, K. M., Jefferies, A. J., and Wlodek, M. E. (2012b). Pregnancy in aged rats that were born small: cardiorenal and metabolic 
adaptations and second-generation fetal growth. FASEB J. 26, 4337-4347. doi: 10.1096/fj.12-210401

Gallo, L. A., Tran, M., Moritz, K. M., Mazzuca, M. Q., Parry, L. J., Westcott, K. T., et al. (2012a). Cardio-renal and metabolic adaptations during pregnancy in female rats born small: implications for maternal health and second generation fetal growth. J. Physiol. 590, 617-630. doi: 10.1113/jphysiol.2011.219147

Gallou-Kabani, C., Gabory, A., Tost, J., Karimi, M., Mayeur, S., Lesage, J., et al. (2010). Sex- and diet-specific changes of imprinted gene expression and DNA methylation in mouse placenta under a high-fat diet. PLoS ONE 5:e14398. doi: 10.1371/journal.pone.0014398

Ganguly, A., Collis, L., and Devaskar, S. U. (2012). Placental glucose and amino acid transport in calorie-restricted wild-type and Glut3 null heterozygous mice. Endocrinology 153, 3995-4007. doi: 10.1210/en.2011-1973

Gao, H., Sathishkumar, K. R., Yallampalli, U., Balakrishnan, M., Li, X., Wu, G., et al. (2012b). Maternal protein restriction regulates IGF2 system in placental labyrinth. Front. Biosci. (Elite Ed). 4, 1434-1450. doi: 10.2741/E472

Gao, H., Yallampalli, U., and Yallampalli, C. (2012a). Gestational protein restriction reduces expression of Hsd17b2 in rat placental labyrinth. Biol. Reprod. 87, 68. doi: 10.1095/biolreprod.112.100479

Gao, H., Yallampalli, U., and Yallampalli, C. (2013). Gestational protein restriction affects trophoblast differentiation. Front. Biosci. (Elite Ed). 5, 591-601. doi: $10.2741 / \mathrm{E} 641$

George, E. M., Garrett, M. R., and Granger, J. P. (2014). Placental ischemia induces changes in gene expression in chorionic tissue. Mamm. Genome 25, 253-261. doi: $10.1007 / \mathrm{s} 00335-014-9505-3$

Gheorghe, C. P., Goyal, R., Holweger, J. D., and Longo, L. D. (2009). Placental gene expression responses to maternal protein restriction in the mouse. Placenta 30, 411-417. doi: 10.1016/j.placenta.2009.03.002

Gheorghe, C. P., Mohan, S., Oberg, K. C., and Longo, L. D. (2007). Gene expression patterns in the hypoxic murine placenta: a role in epigenesis? Reprod. Sci. 14, 223-233. doi: 10.1177/1933719107302860

Ghilardi, N., Ziegler, S., Wiestner, A., Stoffel, R., Heim, M. H., and Skoda, R. C. (1996). Defective STAT signaling by the leptin receptor in diabetic mice. Proc. Natl. Acad. Sci. U.S.A. 93, 6231-6235. doi: 10.1073/pnas.93.13.6231

Gilbert, M., and Leturque, A. (1982). Fetal weight and its relationship to placental blood flow and placental weight in experimental intrauterine growth retardation in the rat. J. Dev. Physiol. 4, 237-246.

Gilbert, R. D., Cummings, L. A., Juchau, M. R., and Longo, L. D. (1979). Placental diffusing capacity and fetal development in exercising or hypoxic guinea pigs. J. Appl. Physiol. Respir. Environ. Exerc. Physiol. 46, 828-834.

Giussani, D. A., Camm, E. J., Niu, Y., Richter, H. G., Blanco, C. E., Gottschalk, R., et al. (2012). Developmental programming of cardiovascular dysfunction by prenatal hypoxia and oxidative stress. PLoS ONE 7:e31017. doi: 10.1371/journal.pone.0031017

Giussani, D. A., Niu, Y., Herrera, E. A., Richter, H. G., Camm, E. J., Thakor, A. S., et al. (2014). Heart disease link to fetal hypoxia and oxidative stress. Adv. Exp. Med. Biol. 814, 77-87. doi: 10.1007/978-1-4939-1031-1_7

Gray, C., Long, S., Green, C., Gardiner, S. M., Craigon, J., and Gardner, D. S. (2013). Maternal fructose and/or salt intake and reproductive outcome in the rat: effects on growth, fertility, sex ratio, and birth order. Biol. Reprod. 89, 51. doi: 10.1095/biolreprod.113.109595

Hanson, M. A., and Gluckman, P. D. (2008). Developmental origins of health and disease: new insights. Basic Clin. Pharmacol. Toxicol. 102, 90-93. doi: 10.1111/j.1742-7843.2007.00186.x

Harper, J. L., Caesar, G. A., Pennington, K. A., Davis, J. W., and Schulz, L. C. (2015). Placental changes caused by food restriction during early pregnancy in mice are reversible. Reprod. Suppl. 150, 165-172. doi: 10.1530/REP-15-0010

Hay, W. W. Jr. (1995). Regulation of placental metabolism by glucose supply. Reprod. Fertil. Dev. 7, 365-375. doi: 10.1071/RD9950365

Hayes, E. K., Lechowicz, A., Petrik, J. J., Storozhuk, Y., Paez-Parent, S., Dai, Q., et al. (2012). Adverse fetal and neonatal outcomes associated with a life-long high fat diet: role of altered development of the placental vasculature. PLoS ONE 7:e33370. doi: 10.1371/journal.pone.0033370

Hayes, E. K., Tessier, D. R., Percival, M. E., Holloway, A. C., Petrik, J. J., Gruslin, A., et al. (2014). Trophoblast invasion and blood vessel remodeling are altered in a rat model of lifelong maternal obesity. Reprod. Sci. 21, 648-657. doi: $10.1177 / 1933719113508815$
Henry, T. Q., Mansano, R. Z., Nast, C. C., Lakshmanan, J., Abdallah, M., AbdelHakeem, A. K., et al. (2010). GDNF and MAPK-ERK pathway signaling is reduced during nephrogenesis following maternal under-nutrition. J. Dev. Orig. Health Dis. 1, 67-74. doi: 10.1017/S2040174409990134

Higgins, J. S., Vaughan, O. R., de Liger, E. F., Fowden, A. L., and SferruzziPerri, A. N. (2015). Placental phenotype and resource allocation to fetal growth are modified by the timing and degree of hypoxia during mouse pregnancy. J. Physiol. doi: 10.1113/JP271057. [Epub ahead of print].

Ho-Chen, J. K., Ain, R., Alt, A. R., Wood, J. G., Gonzalez, N. C., and Soares, M. J. (2006). Hypobaric hypoxia as a tool to study pregnancy-dependent responses at the maternal-fetal interface. Methods Mol. Med. 122, 427-434.

Hoile, S. P., Lillycrop, K. A., Thomas, N. A., Hanson, M. A., and Burdge, G. C. (2011). Dietary protein restriction during F0 pregnancy in rats induces transgenerational changes in the hepatic transcriptome in female offspring. PLoS ONE 6:e21668. doi: 10.1371/journal.pone.0021668

Holemans, K., Caluwaerts, S., Poston, L., and Van Assche, F. A. (2004). Dietinduced obesity in the rat: a model for gestational diabetes mellitus. Am. J. Obstet. Gynecol. 190, 858-865. doi: 10.1016/j.ajog.2003.09.025

Howie, G. J., Sloboda, D. M., Kamal, T., and Vickers, M. H. (2009). Maternal nutritional history predicts obesity in adult offspring independent of postnatal diet. J. Physiol. 587, 905-915. doi: 10.1113/jphysiol.2008.163477

Howie, G. J., Sloboda, D. M., Reynolds, C. M., and Vickers, M. H. (2013). Timing of maternal exposure to a high fat diet and development of obesity and hyperinsulinemia in male rat offspring: same metabolic phenotype, different developmental pathways? J. Nutr. Metab. 2013, 517384. doi: $10.1155 / 2013 / 517384$

Hutter, D., Kingdom, J., and Jaeggi, E. (2010). Causes and mechanisms of intrauterine hypoxia and its impact on the fetal cardiovascular system: a review. Int. J. Pediatr. 2010, 401323. doi: 10.1155/2010/401323

Hvizdosova-Klescova, A., Uhlik, J., Malina, M., Vulterinova, H., Novotny, T., and Vajner, L. (2013). Remodeling of fetoplacental arteries in rats due to chronic hypoxia. Exp. Toxicol. Pathol. 65, 97-103. doi: 10.1016/j.etp.2011.06.006

Igosheva, N., Abramov, A. Y., Poston, L., Eckert, J. J., Fleming, T. P., Duchen, M. R., et al. (2010). Maternal diet-induced obesity alters mitochondrial activity and redox status in mouse oocytes and zygotes. PLoS ONE 5:e10074. doi: 10.1371/journal.pone.0010074

Intapad, S., Warrington, J. P., Spradley, F. T., Palei, A. C., Drummond, H. A., Ryan, M. J., et al. (2014). Reduced uterine perfusion pressure induces hypertension in the pregnant mouse. Am. J. Physiol. Regul. Integr. Comp. Physiol. 307, R1353-R1357. doi: 10.1152/ajpregu.00268.2014

Itoh, S., Brawley, L., Wheeler, T., Anthony, F. W., Poston, L., and Hanson, M. A. (2002). Vasodilation to vascular endothelial growth factor in the uterine artery of the pregnant rat is blunted by low dietary protein intake. Pediatr. Res. 51, 485-491. doi: 10.1203/00006450-200204000-00014

Jansson, N., Pettersson, J., Haafiz, A., Ericsson, A., Palmberg, I., Tranberg, M., et al. (2006). Down-regulation of placental transport of amino acids precede the development of intrauterine growth restriction in rats fed a low protein diet. J. Physiol. 576, 935-946. doi: 10.1113/jphysiol.2003.550004

Jansson, T., and Powell, T. L. (2006). IFPA 2005 Award in Placentology Lecture. Human placental transport in altered fetal growth: does the placenta function as a nutrient sensor? - a review. Placenta 27(Suppl. A), S91-S97. doi: 10.1016/j.placenta.2005.11.010

Jones, H. N., Woollett, L. A., Barbour, N., Prasad, P. D., Powell, T. L., and Jansson, T. (2008). High-fat diet before and during pregnancy causes marked up-regulation of placental nutrient transport and fetal overgrowth in C57/BL6 mice. FASEB J. 23, 271-278. doi: 10.1096/fj.08-116889

Jungheim, E. S., Schoeller, E. L., Marquard, K. L., Louden, E. D., Schaffer, J. E., and Moley, K. H. (2010). Diet-induced obesity model: abnormal oocytes and persistent growth abnormalities in the offspring. Endocrinology 151, 4039-4046. doi: 10.1210/en.2010-0098

Kane, A. D., Herrera, E. A., Camm, E. J., and Giussani, D. A. (2013). Vitamin C prevents intrauterine programming of in vivo cardiovascular dysfunction in the rat. Circul. J. 77, 2604-2611. doi: 10.1253/circj.CJ-13-0311

Keesey, R. E., and Hirvonen, M. D. (1997). Body weight set-points: determination and adjustment. J. Nutr. 127, 1875S-1883S.

Khorram, N. M., Magee, T. R., Wang, C., Desai, M., Ross, M., and Khorram, O. (2011). Maternal undernutrition programs offspring adrenal 
expression of steroidogenic enzymes. Reprod. Sci. 18, 931-940. doi: $10.1177 / 1933719111404613$

Khorram, O., Han, G., Bagherpour, R., Magee, T. R., Desai, M., Ross, M. G., et al. (2010). Effect of maternal undernutrition on vascular expression of micro and messenger RNA in newborn and aging offspring. Am. J. Physiol. Regul. Integr. Comp. Physiol. 298, R1366-R1374. doi: 10.1152/ajpregu.00704.2009

Khorram, O., Keen-Rinehart, E., Chuang, T. D., Ross, M. G., and Desai, M. (2015). Maternal undernutrition induces premature reproductive senescence in adult female rat offspring. Fertil. Steril. 103, 291-8 e2. doi: 10.1016/j.fertnstert.2014.09.026

Khorram, O., Khorram, N., Momeni, M., Han, G., Halem, J., Desai, M., et al. (2007b). Maternal undernutrition inhibits angiogenesis in the offspring: a potential mechanism of programmed hypertension. Am. J. Physiol. Regul. Integr. Comp. Physiol. 293, R745-R753. doi: 10.1152/ajpregu.00131.2007

Khorram, O., Momeni, M., Desai, M., and Ross, M. G. (2007a). Nutrient restriction in utero induces remodeling of the vascular extracellular matrix in rat offspring. Reprod. Sci. 14, 73-80. doi: 10.1177/1933719106298215

Kim, D. W., Young, S. L., Grattan, D. R., and Jasoni, C. L. (2014). Obesity during pregnancy disrupts placental morphology, cell proliferation, and inflammation in a sex-specific manner across gestation in the mouse. Biol. Reprod. 90, 130. doi: 10.1095/biolreprod.113.117259

Kind, K. L., Clifton, P. M., Grant, P. A., Owens, P. C., Sohlstrom, A., Roberts, C. T., et al. (2003). Effect of maternal feed restriction during pregnancy on glucose tolerance in the adult guinea pig. Am. J. Physiol. Regul. Integr. Comp. Physiol. 284, R140-R152. doi: 10.1152/ajpregu.00587.2001

Kind, K. L., Clifton, P. M., Katsman, A. I., Tsiounis, M., Robinson, J. S., and Owens, J. A. (1999). Restricted fetal growth and the response to dietary cholesterol in the guinea pig. Am. J. Physiol. 277, R1675-R1682.

Kind, K. L., Roberts, C. T., Sohlstrom, A. I., Katsman, A., Clifton, P. M., Robinson, J. S., et al. (2005). Chronic maternal feed restriction impairs growth but increases adiposity of the fetal guinea pig. Am. J. Physiol. Regul. Integr. Comp. Physiol. 288, R119-R126. doi: 10.1152/ajpregu.00360.2004

Kind, K. L., Simonetta, G., Clifton, P. M., Robinson, J. S., and Owens, J. A. (2002). Effect of maternal feed restriction on blood pressure in the adult guinea pig. Exp. Physiol. 87, 469-477. doi: 10.1111/j.1469-445X.2002.tb00060.x

King, V., Hibbert, N., Seckl, J. R., Norman, J. E., and Drake, A. J. (2013). The effects of an obesogenic diet during pregnancy on fetal growth and placental gene expression are gestation dependent. Placenta 34, 1087-1090. doi: 10.1016/j.placenta.2013.09.006

Kwong, W. Y., Miller, D. J., Ursell, E., Wild, A. E., Wilkins, A. P., Osmond, C., et al. (2006). Imprinted gene expression in the rat embryo-fetal axis is altered in response to periconceptional maternal low protein diet. Reprod. Suppl. 132, 265-277. doi: 10.1530/rep.1.01038

Kwong, W. Y., Wild, A. E., Roberts, P., Willis, A. C., and Fleming, T. P. (2000). Maternal undernutrition during the preimplantation period of rat development causes blastocyst abnormalities and programming of postnatal hypertension. Development 127, 4195-4202.

Laborie, C., Molendi-Coste, O., Breton, C., Montel, V., Vandenbulcke, F., Grumolato, L., et al. (2011). Maternal perinatal undernutrition has longterm consequences on morphology, function and gene expression of the adrenal medulla in the adult male rat. J. Neuroendocrinol. 23, 711-724. doi: 10.1111/j.1365-2826.2011.02159.x

Lager, S., and Powell, T. L. (2012). Regulation of nutrient transport across the placenta. J. Pregnancy 2012, 179827. doi: 10.1155/2012/179827

Lager, S., Samulesson, A. M., Taylor, P. D., Poston, L., Powell, T. L., and Jansson, T. (2014). Diet-induced obesity in mice reduces placental efficiency and inhibits placental mTOR signaling. Physiol. Rep. 2, e00242. doi: 10.1002/phy2.242

Lauritz, B., Siebel, A. L., Guille, V., Jefferies, A. J., and Wlodek, M. E. (2012). Growth restriction alters adult spatial memory and sensorimotor gating in a sex-specific manner. J. Dev. Orig. Health Dis. 3, 59-68. doi: $10.1017 /$ S2040174411000729

Leonhardt, M., Lesage, J., Croix, D., Dutriez-Casteloot, I., Beauvillain, J. C., and Dupouy, J. P. (2003). Effects of perinatal maternal food restriction on pituitary-gonadal axis and plasma leptin level in rat pup at birth and weaning and on timing of puberty. Biol. Reprod. 68, 390-400. doi: 10.1095/biolreprod.102.003269

Leonhardt, M., Lesage, J., Dufourny, L., Dickes-Coopman, A., Montel, V., and Dupouy, J. P. (2002). Perinatal maternal food restriction induces alterations in hypothalamo-pituitary-adrenal axis activity and in plasma corticosteronebinding globulin capacity of weaning rat pups. Neuroendocrinology 75, 45-54. doi: 10.1159/000048220

Lesage, J., Blondeau, B., Grino, M., Breant, B., and Dupouy, J. P. (2001). Maternal undernutrition during late gestation induces fetal overexposure to glucocorticoids and intrauterine growth retardation, and disturbs the hypothalamo-pituitary adrenal axis in the newborn rat. Endocrinology 142, 1692-1702. doi: 10.1210/en.142.5.1692

Lesage, J., Dufourny, L., Laborie, C., Bernet, F., Blondeau, B., Avril, I., et al. (2002b). Perinatal malnutrition programs sympathoadrenal and hypothalamicpituitary-adrenal axis responsiveness to restraint stress in adult male rats. J. Neuroendocrinol. 14, 135-143. doi: 10.1046/j.0007-1331.2001.00753.x

Lesage, J., Hahn, D., Leonhardt, M., Blondeau, B., Breant, B., and Dupouy, J. P. (2002a). Maternal undernutrition during late gestation-induced intrauterine growth restriction in the rat is associated with impaired placental GLUT3 expression, but does not correlate with endogenous corticosterone levels. J. Endocrinol. 174, 37-43. doi: 10.1677/joe.0.1740037

Lewis, R. M., Doherty, C. B., James, L. A., Burton, G. J., and Hales, C. N. (2001a). Effects of maternal iron restriction on placental vascularization in the rat. Placenta 22, 534-539. doi: 10.1053/plac.2001.0679

Lewis, R. M., Forhead, A. J., Petry, C. J., Ozanne, S. E., and Hales, C. N. (2002). Long-term programming of blood pressure by maternal dietary iron restriction in the rat. Br. J. Nutr. 88, 283-290. doi: 10.1079/BJN2002656

Lewis, R. M., James, L. A., Zhang, J., Byrne, C. D., and Hales, C. N. (2001b). Effects of maternal iron restriction in the rat on hypoxia-induced gene expression and fetal metabolite levels. Br. J. Nutr. 85, 193-201. doi: 10.1079/BJN2000247

Lewis, R. M., Petry, C. J., Ozanne, S. E., and Hales, C. N. (2001c). Effects of maternal iron restriction in the rat on blood pressure, glucose tolerance, and serum lipids in the 3-month-old offspring. Metab. Clin. Exp. 50, 562-567. doi: 10.1053/meta.2001.22516

Li, H. P., Chen, X., and Li, M. Q. (2013). Gestational diabetes induces chronic hypoxia stress and excessive inflammatory response in murine placenta. Int J. Clin. Exp. Pathol. 6, 650-659.

Liang, C., DeCourcy, K., and Prater, M. R. (2010). High-saturated-fat diet induces gestational diabetes and placental vasculopathy in C57BL/6 mice. Metab. Clin. Exp. 59, 943-950. doi: 10.1016/j.metabol.2009.10.015

Liang, C., Oest, M. E., Jones, J. C., and Prater, M. R. (2009a). Gestational high saturated fat diet alters C57BL/6 mouse perinatal skeletal formation. Birth Defects Res. B Dev. Reprod. Toxicol. 86, 362-369. doi: 10.1002/bdrb.20204

Liang, C., Oest, M. E., and Prater, M. R. (2009b). Intrauterine exposure to high saturated fat diet elevates risk of adult-onset chronic diseases in C57BL/6 mice. Birth Defects Res. B Dev. Reprod. Toxicol. 86, 377-384. doi: 10.1002/bdrb.20206

Lillycrop, K. A., and Burdge, G. C. (2011). Epigenetic changes in early life and future risk of obesity. Int. J. Obes. 35, 72-83. doi: 10.1038/ijo.2010.122

Lillycrop, K. A., Phillips, E. S., Jackson, A. A., Hanson, M. A., and Burdge, G. C. (2005). Dietary protein restriction of pregnant rats induces and folic acid supplementation prevents epigenetic modification of hepatic gene expression in the offspring. J. Nutr. 135, 1382-1386.

Lillycrop, K. A., Phillips, E. S., Torrens, C., Hanson, M. A., Jackson, A. A., and Burdge, G. C. (2008). Feeding pregnant rats a protein-restricted diet persistently alters the methylation of specific cytosines in the hepatic PPAR alpha promoter of the offspring. Br. J. Nutr. 100, 278-282. doi: 10.1017/S0007114507894438

Lillycrop, K. A., Slater-Jefferies, J. L., Hanson, M. A., Godfrey, K. M., Jackson, A. A., and Burdge, G. C. (2007). Induction of altered epigenetic regulation of the hepatic glucocorticoid receptor in the offspring of rats fed a proteinrestricted diet during pregnancy suggests that reduced DNA methyltransferase1 expression is involved in impaired DNA methylation and changes in histone modifications. Br. J. Nutr. 97, 1064-1073. doi: 10.1017/S0007114507 69196X

Lin, Y., Han, X. F., Fang, Z. F., Che, L. Q., Nelson, J., Yan, T. H., et al. (2011). Beneficial effects of dietary fibre supplementation of a highfat diet on fetal development in rats. Br. J. Nutr. 106, 510-518. doi: 10.1017/S0007114511000614

Lineker, C., Kerr, P. M., Nguyen, P., Bloor, I., Astbury, S., Patel, N., et al. (2015). High fructose consumption in pregnancy alters the perinatal environment without increasing metabolic disease in the offspring. Reprod. Fertil. Dev. doi: 10.1071/RD15119. [Epub ahead of print] 
Liu, X., Lin, Y., Tian, B., Miao, J., Xi, C., and Liu, C. (2014). Maternal protein restriction alters VEGF signaling and decreases pulmonary alveolar in fetal rats. Int. J. Clin. Exp. Pathol. 7, 3101-3111.

Lueder, F. L., Kim, S. B., Buroker, C. A., Bangalore, S. A., and Ogata, E. S. (1995). Chronic maternal hypoxia retards fetal growth and increases glucose utilization of select fetal tissues in the rat. Metab. Clin. Exp. 44, 532-537. doi: 10.1016/0026-0495(95)90063-2

Lukaszewski, M. A., Butruille, L., Moitrot, E., Montel, V., Dickes-Coopman, A., Lesage, J., et al. (2013). The hypothalamic POMC mRNA expression is upregulated in prenatally undernourished male rat offspring under high-fat diet. Peptides 43, 146-154. doi: 10.1016/j.peptides.2013.03.013

Lukaszewski, M. A., Mayeur, S., Fajardy, I., Delahaye, F., Dutriez-Casteloot, I., Montel, V., et al. (2011). Maternal prenatal undernutrition programs adipose tissue gene expression in adult male rat offspring under high-fat diet. Am. J. Physiol. Endocrinol. Metab. 301, E548-E559. doi: 10.1152/ajpendo.00011.2011

Luzzo, K. M., Wang, Q., Purcell, S. H., Chi, M., Jimenez, P. T., Grindler, N., et al. (2012). High fat diet induced developmental defects in the mouse: oocyte meiotic aneuploidy and fetal growth retardation/brain defects. PLoS ONE 7:e49217. doi: 10.1371/journal.pone.0049217

Magee, T. R., Han, G., Cherian, B., Khorram, O., Ross, M. G., and Desai, M. (2008). Down-regulation of transcription factor peroxisome proliferator-activated receptor in programmed hepatic lipid dysregulation and inflammation in intrauterine growth-restricted offspring. Am. J. Obstet. Gynecol. 199, 271 e1-5. doi: 10.1016/j.ajog.2008.05.022

Malandro, M. S., Beveridge, M. J., Kilberg, M. S., and Novak, D. A. (1996a). Effect of low-protein diet-induced intrauterine growth retardation on rat placental amino acid transport. Am. J. Physiol. 271, C295-303.

Malandro, M. S., Beveridge, M. J., Novak, D. A., and Kilberg, M. S. (1996b). Rat placental amino acid transport after protein-deprivation-induced intrauterine growth retardation. Biochem. Soc. Trans. 24, 839-843.

Mark, P. J., Sisala, C., Connor, K., Patel, R., Lewis, J. L., Vickers, M., et al. (2011). A maternal high-fat diet in rat pregnancy reduces growth of the fetus and the placental junctional zone, but not placental labyrinth zone growth. J. Dev. Orig. Hlth. Dis. 2, 63-70. doi: 10.1017/S2040174410000681

Master, J. S., Zimanyi, M. A., Yin, K. V., Moritz, K. M., Gallo, L. A., Tran, M., et al. (2014). Transgenerational left ventricular hypertrophy and hypertension in offspring after uteroplacental insufficiency in male rats. Clin. Exp. Pharmacol. Physiol. 41, 884-890. doi: 10.1111/1440-1681.12303

Matheson, H., Veerbeek, J. H., Charnock-Jones, D. S., Burton, G. J., and Yung, H. W. (2015). Morphological and molecular changes in the murine placenta exposed to normobaric hypoxia throughout pregnancy. J. Physiol. doi: 10.1113/JP271073. [Epub ahead of print].

Mayeur, S., Lancel, S., Theys, N., Lukaszewski, M. A., Duban, S., Bastide, B., et al. (2012). Maternal calorie restriction modulates placental mitochondrial biogenesis and bioenergetic efficiency: involvement in feto-placental growth defects in rats. Am. J. Physiol. Endocrinol. Metab. 304, E14-E22. doi: 10.1152/ajpendo.00332.2012

Mazzuca, M. Q., Tare, M., Parkington, H. C., Dragomir, N. M., Parry, L. J., and Wlodek, M. E. (2012). Uteroplacental insufficiency programmes vascular dysfunction in non-pregnant rats: compensatory adaptations in pregnancy. J. Physiol. 590, 3375-3388. doi: 10.1113/jphysiol.2012.230011

Mazzuca, M. Q., Wlodek, M. E., Dragomir, N. M., Parkington, H. C., and Tare, M. (2010). Uteroplacental insufficiency programs regional vascular dysfunction and alters arterial stiffness in female offspring. J. Physiol. 588, 1997-2010. doi: 10.1113/jphysiol.2010.187849

Mazzucco, M. B., Fornes, D., Capobianco, E., Higa, R., Jawerbaum, A., and White, V. (2016). Maternal saturated-fat-rich diet promotes leptin resistance in fetal liver lipid catabolism and programs lipid homeostasis impairments in the liver of rat offspring. J. Nutr Biochem. 27, 61-69. doi: 10.1016/j.jnutbio.2015.08.019

Mazzucco, M. B., Higa, R., Capobianco, E., Kurtz, M., Jawerbaum, A., and White, V. (2013). Saturated fat-rich diet increases fetal lipids and modulates LPL and leptin receptor expression in rat placentas. J. Endocrinol. 217, 303-315. doi: 10.1530/JOE-13-0021

McMillen, I. C., and Robinson, J. S. (2005). Developmental origins of the metabolic syndrome: prediction, plasticity, and programming. Physiol. Rev. 85, 571-633. doi: 10.1152/physrev.00053.2003

Minge, C. E., Bennett, B. D., Norman, R. J., and Robker, R. L. (2008). Peroxisome Proliferator-Activated Receptor-\{gamma\} Agonist Rosiglitazone Reverses the Adverse Effects of Diet-Induced Obesity on Oocyte Quality. Endocrinology 149, 2646-2656. doi: 10.1210/en.2007-1570
Mitchell, M., Schulz, S. L., Armstrong, D. T., and Lane, M. (2009). Metabolic and mitochondrial dysfunction in early mouse embryos following maternal dietary protein intervention. Biol. Reprod. 80, 622-630. doi: 10.1095/biolreprod.108.072595

Moraes, C., Rebelato, H. J., Amaral, M. E., Resende, T. M., Silva, E. V., Esquisatto, M. A., et al. (2014). Effect of maternal protein restriction on liver metabolism in rat offspring. J. Physiol. Sci. 64, 347-355. doi: 10.1007/s12576-0140325-8

Moritz, K. M., Mazzuca, M. Q., Siebel, A. L., Mibus, A., Arena, D., Tare, M., et al. (2009). Uteroplacental insufficiency causes a nephron deficit, modest renal insufficiency but no hypertension with ageing in female rats. J. Physiol. 587, 2635-2646. doi: 10.1113/jphysiol.2009.170407

Mukai, Y., Kumazawa, M., and Sato, S. (2013). Fructose intake during pregnancy up-regulates the expression of maternal and fetal hepatic sterol regulatory element-binding protein-1c in rats. Endocrine 44, 79-86. doi: 10.1007/s12020012-9815-8

O’Dowd, R., Kent, J. C., Moseley, J. M., and Wlodek, M. E. (2008). Effects of uteroplacental insufficiency and reducing litter size on maternal mammary function and postnatal offspring growth. Am. J. Physiol. Regul. Integr. Comp. Physiol. 294, R539-R548. doi: 10.1152/ajpregu.00628.2007

Ojeda, N. B., Grigore, D., Robertson, E. B., and Alexander, B. T. (2007). Estrogen protects against increased blood pressure in postpubertal female growth restricted offspring. Hypertension 50, 679-685. doi: 10.1161/HYPERTENSIONAHA.107.091785

Ojeda, N. B., Intapad, S., and Alexander, B. T. (2014). Sex differences in the developmental programming of hypertension. Acta Physiol. (Oxf). 210, 307-316. doi: 10.1111/apha.12206

Qiao, L., Guo, Z., Bosco, C., Guidotti, S., Wang, Y., Wang, M., et al. (2015). Maternal high fat feeding increases placenta lipoprotein lipase activity by reducing sirt1 expression in mice. Diabetes 64, 3111-3120. doi: 10.2337/db141627

Qiao, L., Yoo, H. S., Madon, A., Kinney, B., Hay, W. W. Jr., and Shao, J. (2012). Adiponectin enhances mouse fetal fat deposition. Diabetes 61, 3199-3207. doi: $10.2337 / \mathrm{db} 12-0055$

Rebelato, H. J., Esquisatto, M. A., Moraes, C., Amaral, M. E., and Catisti, R. (2013). Gestational protein restriction induces alterations in placental morphology and mitochondrial function in rats during late pregnancy. J. Mol. Histol. 44, 629-637. doi: 10.1007/s10735-013-9522-7

Rebholz, S. L., Burke, K. T., Yang, Q., Tso, P., and Woollett, L. A. (2011). Dietary fat impacts fetal growth and metabolism: uptake of chylomicron remnant core lipids by the placenta. Am. J. Physiol. Endocrinol. Metab. 301, E416-E425. doi: 10.1152/ajpendo.00619.2010

Rees, S., Harding, R., and Walker, D. (2008). An adverse intrauterine environment: implications for injury and altered development of the brain. Intern. J. Dev. Neurosci. 26, 3-11. doi: 10.1016/j.ijdevneu.2007.08.020

Reid, G. J., Lane, R. H., Flozak, A. S., and Simmons, R. A. (1999). Placental expression of glucose transporter proteins 1 and 3 in growth-restricted fetal rats. Am. J. Obstet. Gynecol. 180, 1017-1023. doi: 10.1016/S00029378(99)70675-7

Reynolds, C. M., Vickers, M. H., Harrison, C. J., Segovia, S. A., and Gray, C. (2015). Maternal high fat and/or salt consumption induces sex-specific inflammatory and nutrient transport in the rat placenta. Physiol. Rep. 3:e12399. doi: 10.14814/phy2.12399

Richter, H. G., Camm, E. J., Modi, B. N., Naeem, F., Cross, C. M., Cindrova-Davies, T., et al. (2012). Ascorbate prevents placental oxidative stress and enhances birth weight in hypoxic pregnancy in rats. J. Physiol. 590, 1377-1387. doi: 10.1113/jphysiol.2011.226340

Richter, H. G., Hansell, J. A., Raut, S., and Giussani, D. A. (2009). Melatonin improves placental efficiency and birth weight and increases the placental expression of antioxidant enzymes in undernourished pregnancy. J. Pineal Res. 46, 357-364. doi: 10.1111/j.1600-079X.2009.00671.x

Riviere, G., Michaud, A., Breton, C., VanCamp, G., Laborie, C., Enache, M., et al. (2005). Angiotensin-converting enzyme 2 (ACE2) and ACE activities display tissue-specific sensitivity to undernutrition-programmed hypertension in the adult rat. Hypertension 46, 1169-1174. doi: 10.1161/01.HYP.0000185148.27901.fe

Roberts, C. T., Sohlstrom, A., Kind, K. L., Earl, R. A., Khong, T. Y., Robinson, J. S., et al. (2001). Maternal food restriction reduces the exchange surface area and increases the barrier thickness of the placenta in the guinea-pig. Placenta 22, 177-185. doi: 10.1053/plac.2000.0602 
Rodford, J. L., Torrens, C., Siow, R. C., Mann, G. E., Hanson, M. A., and Clough, G. F. (2008). Endothelial dysfunction and reduced antioxidant protection in an animal model of the developmental origins of cardiovascular disease. J. Physiol. 586, 4709-4720. doi: 10.1113/jphysiol.2008.156976

Romano, T., Hryciw, D. H., Westcott, K. T., and Wlodek, M. E. (2015). Puberty onset is delayed following uteroplacental insufficiency and occurs earlier with improved lactation and growth for pups born small. Reprod. Fertil. Dev. doi: 10.1071/RD15151. [Epub ahead of print].

Romano, T., Wark, J. D., and Wlodek, M. E. (2014). Developmental programming of bone deficits in growth-restricted offspring. Reprod. Fertil. Dev. doi: 10.1071/RD13388. [Epub ahead of print].

Rosario, F. J., Jansson, N., Kanai, Y., Prasad, P. D., Powell, T. L., and Jansson, T. (2011). Maternal protein restriction in the rat inhibits placental insulin, mTOR, and STAT3 signaling and down-regulates placental amino acid transporters. Endocrinology 152, 1119-1129. doi: 10.1210/en.2010-1153

Rosario, G. X., Konno, T., and Soares, M. J. (2008). Maternal hypoxia activates endovascular trophoblast cell invasion. Dev. Biol. 314, 362-375. doi: 10.1016/j.ydbio.2007.12.007

Rosso, P. (1977a). Maternal-fetal exchange during protein malnutrition in the rat. Placental transfer of glucose and a nonmetabolizable glucose analog. J. Nutr. 107, 20006-20010.

Rosso, P. (1977b). Maternal-fetal exchange during protein malnutrition in the rat. Placental transfer of alpha-amino isobutyric acid. J. Nutr. 107, 2002-2005.

Rueda-Clausen, C. F., Stanley, J. L., Thambiraj, D. F., Poudel, R., Davidge, S. T., and Baker, P. N. (2014). Effect of prenatal hypoxia in transgenic mouse models of preeclampsia and fetal growth restriction. Reprod. Sci. 21, 492-502. doi: $10.1177 / 1933719113503401$

Rutland, C. S., Latunde-Dada, A. O., Thorpe, A., Plant, R., Langley-Evans, S., and Leach, L. (2007). Effect of gestational nutrition on vascular integrity in the murine placenta. Placenta 28, 734-742. doi: 10.1016/j.placenta.2006.07.001

Sasson, I. E., Vitins, A. P., Mainigi, M. A., Moley, K. H., and Simmons, R. A. (2015). Pre-gestational vs gestational exposure to maternal obesity differentially programs the offspring in mice. Diabetologia 58, 615-624. doi: 10.1007/s00125014-3466-7

Sathishkumar, K., Balakrishnan, M. P., and Yallampalli, C. (2015). Enhanced mesenteric arterial responsiveness to angiotensin II is androgen receptordependent in prenatally protein-restricted adult female rat offspring. Biol. Reprod. 92, 55. doi: 10.1095/biolreprod.114.126482

Sathishkumar, K., Elkins, R., Yallampalli, U., and Yallampalli, C. (2009). Protein restriction during pregnancy induces hypertension and impairs endotheliumdependent vascular function in adult female offspring. J. Vasc. Res. 46, 229-239. doi: $10.1159 / 000166390$

Sathishkumar, K., Elkins, R., Yallampalli, U., and Yallampalli, C. (2012). Protein restriction during pregnancy induces hypertension in adult female rat offspring-influence of oestradiol. Br. J. Nutr. 107, 665-673. doi: $10.1017 /$ S0007114511003448

Schlitt, J. M., and Schulz, L. C. (2012). The source of leptin, but not leptin depletion in response to food restriction, changes during early pregnancy in mice. Endocrine 41, 227-235. doi: 10.1007/s12020-011-9548-0

Schulz, L. C., Schlitt, J. M., Caesar, G., and Pennington, K. A. (2012). Leptin and the placental response to maternal food restriction during early pregnancy in mice. Biol. Reprod. 87, 120. doi: 10.1095/biolreprod.112.103218

Sebaai, N., Lesage, J., Alaoui, A., Dupouy, J. P., and Deloof, S. (2002b). Effects of dehydration on endocrine regulation of the electrolyte and fluid balance and atrial natriuretic peptide-binding sites in perinatally malnourished adult male rats. Eur. J. Endocrinol. 147, 835-848. doi: 10.1530/eje.0.1470835

Sebaai, N., Lesage, J., Breton, C., Vieau, D., and Deloof, S. (2004). Perinatal food deprivation induces marked alterations of the hypothalamo-pituitaryadrenal axis in 8-month-old male rats both under basal conditions and after a dehydration period. Neuroendocrinology 79, 163-173. doi: 10.1159/000078098

Sebaai, N., Lesage, J., Vieau, D., Alaoui, A., Dupouy, J. P., and Deloof, S. (2002a). Altered control of the hypothalamo-pituitary-adrenal axis in adult male rats exposed perinatally to food deprivation and/or dehydration. Neuroendocrinology 76, 243-253. doi: 10.1159/000065947

Sferruzzi-Perri, A. N., Vaughan, O. R., Coan, P. M., Suciu, M. C., Darbyshire, R., Constancia, M., et al. (2011). Placental-specific Igf2 deficiency alters developmental adaptations to undernutrition in mice. Endocrinology 152, 3202-3212. doi: 10.1210/en.2011-0240
Sferruzzi-Perri, A. N., Vaughan, O. R., Haro, M., Cooper, W. N., Musial, B., Charalambous, M., et al. (2013). An obesogenic diet during mouse pregnancy modifies maternal nutrient partitioning and the fetal growth trajectory. FASEB 27, 3928-3937. doi: 10.1096/fj.13-234823

Sibley, C., Glazier, J., and D'Souza, S. (1997). Placental transporter activity and expression in relation to fetal growth. Exp. Physiol. 82, 389-402. doi: 10.1113/expphysiol.1997.sp004034

Siebel, A. L., Gallo, L. A., Guan, T. C., Owens, J. A., and Wlodek, M. E. (2010). Cross-fostering and improved lactation ameliorates deficits in endocrine pancreatic morphology in growth-restricted adult male rat offspring. J. Dev. Orig. Health Dis. 1, 234-244. doi: 10.1017/S2040174410000383

Siebel, A. L., Mibus, A., De Blasio, M. J., Westcott, K. T., Morris, M. J., Prior, L., et al. (2008). Improved lactational nutrition and postnatal growth ameliorates impairment of glucose tolerance by uteroplacental insufficiency in male rat offspring. Endocrinology 149, 3067-3076. doi: 10.1210/en.20 08-0128

Skeffington, K. L., Higgins, J. S., Mahmoud, A. D., Evans, A. M., Sferruzzi-Perri, A. N., Fowden, A. L., et al. (2015). Hypoxia, AMPK activation and uterine artery vasoreactivity. J. Physiol. doi: 10.1113/JP270995. [Epub ahead of print].

Slater-Jefferies, J. L., Lillycrop, K. A., Townsend, P. A., Torrens, C., Hoile, S. P., Hanson, M. A., et al. (2011). Feeding a protein-restricted diet during pregnancy induces altered epigenetic regulation of peroxisomal proliferatoractivated receptor-alpha in the heart of the offspring. J. Dev. Orig. Health Dis. 2, 250-255. doi: 10.1017/S2040174410000425

Sloboda, D. M., Howie, G. J., Pleasants, A., Gluckman, P. D., and Vickers, M. H. (2009). Pre- and postnatal nutritional histories influence reproductive maturation and ovarian function in the rat. PLOS ONE 4:e6744. doi: 10.1371/journal.pone.0006744

Smart, J. L., Dobbing, J., Adlard, B. P., Lynch, A., and Sands, J. (1973). Vulnerability of developing brain: relative effects of growth restriction during the fetal and suckling periods on behavior and brain composition of adult rats. J. Nutr. 103, 1327-1338.

Smith, T., Sloboda, D. M., Saffery, R., Joo, E., and Vickers, M. H. (2014). Maternal nutritional history modulates the hepatic IGF-IGFBP axis in adult male rat offspring. Endocrine 46, 70-82. doi: 10.1007/s12020-013-0034-8

Sohlstrom, A., Fernberg, P., Owens, J. A., and Owens, P. C. (2001). Maternal nutrition affects the ability of treatment with IGF-I and IGF-II to increase growth of the placenta and fetus, in guinea pigs. Growth Horm. IGF Res. 11, 392-398. doi: 10.1054/ghir.2001.0253

Sohlstrom, A., Katsman, A., Kind, K. L., Grant, P. A., Owens, P. C., Robinson, J. S., et al. (1998a). Effects of acute and chronic food restriction on the insulin-like growth factor axis in the guinea pig. J. Endocrinol. 157, 107-114.

Sohlstrom, A., Katsman, A., Kind, K. L., Roberts, C. T., Owens, P. C., Robinson, J. S., et al. (1998b). Food restriction alters pregnancy-associated changes in IGF and IGFBP in the guinea pig. Am. J. Physiol. 274, E410-E416.

Soo, P. S., Hiscock, J., Botting, K. J., Roberts, C. T., Davey, A. K., and Morrison, J. L. (2012). Maternal undernutrition reduces P-glycoprotein in guinea pig placenta and developing brain in late gestation. Reprod. Toxicol. 33, 374-381. doi: 10.1016/j.reprotox.2012.01.013

Strakovsky, R. S., Zhou, D., and Pan, Y. X. (2010). A low-protein diet during gestation in rats activates the placental mammalian amino acid response pathway and programs the growth capacity of offspring. J. Nutr. 140, 2116-2120. doi: 10.3945/jn.110.127803

Sun, C., Velazquez, M. A., Marfy-Smith, S., Sheth, B., Cox, A., Johnston, D. A., et al. (2014). Mouse early extra-embryonic lineages activate compensatory endocytosis in response to poor maternal nutrition. Development 141, 1140-1150. doi: $10.1242 /$ dev.103952

Susser, E., and St Clair, D. (2013). Prenatal famine and adult mental illness: interpreting concordant and discordant results from the Dutch and Chinese Famines. Soc. Sci. Med. 97, 325-330. doi: 10.1016/j.socscimed.2013.02.049

Tafti, S. A., Nast, C. C., Desai, M., Amaya, K. E., Ross, M. G., and Magee, T. R. (2011). Maternal undernutrition upregulates apoptosis in offspring nephrogenesis. J. Dev. Orig. Health Dis. 2, 226-235. doi: 10.1017/S2040174411000262

Tare, M., Parkington, H. C., Bubb, K. J., and Wlodek, M. E. (2012). Uteroplacental insufficiency and lactational environment separately influence arterial stiffness and vascular function in adult male rats. Hypertension 60, 378-386. doi: 10.1161/HYPERTENSIONAHA.112.190876 
Tarry-Adkins, J. L., Chen, J. H., Smith, N. S., Jones, R. H., Cherif, H., and Ozanne, S. E. (2009). Poor maternal nutrition followed by accelerated postnatal growth leads to telomere shortening and increased markers of cell senescence in rat islets. FASEB J. 23, 1521-1528. doi: 10.1096/fj.08-122796

Taylor, P. D., Khan, I. Y., Lakasing, L., Dekou, V., O'Brien-Coker, I., Mallet, A. I., et al. (2003). Uterine artery function in pregnant rats fed a diet supplemented with animal lard. Exp. Physiol. 88, 389-398. doi: 10.1113/eph8802495

Tissot van Patot, M. C., Murray, A. J., Beckey, V., Cindrova-Davies, T., Johns, J., Zwerdlinger, L., et al. (2010). Human placental metabolic adaptation to chronic hypoxia, high altitude: hypoxic preconditioning. Am. J. Physiol. Regul. Integr. Comp. Physiol. 298, R166-R172. doi: 10.1152/ajpregu.00383.2009

Torrens, C., Brawley, L., Anthony, F. W., Dance, C. S., Dunn, R., Jackson, A. A., et al. (2006). Folate supplementation during pregnancy improves offspring cardiovascular dysfunction induced by protein restriction. Hypertension 47, 982-987. doi: 10.1161/01.HYP.0000215580.43711.d1

Torrens, C., Poston, L., and Hanson, M. A. (2008). Transmission of raised blood pressure and endothelial dysfunction to the $\mathrm{F} 2$ generation induced by maternal protein restriction in the $\mathrm{F} 0$, in the absence of dietary challenge in the $\mathrm{F} 1$ generation. Br. J. Nutr. 100, 760-766. doi: 10.1017/S0007114508921747

Tran, M., Gallo, L. A., Wadley, G. D., Jefferies, A. J., Moritz, K. M., and Wlodek, M. E. (2012). Effect of pregnancy for females born small on later life metabolic disease risk. PLoS ONE 7:e45188. doi: 10.1371/annotation/0a0f4d8b-8ec34d62-8d0b-1917716beaa0

Tran, M., Young, M. E., Jefferies, A. J., Hryciw, D. H., Ward, M. M., Fletcher, E. L., et al. (2015). Uteroplacental insufficiency leads to hypertension, but not glucose intolerance or impaired skeletal muscle mitochondrial biogenesis, in 12-month-old rats. Physiol. Rep. 3:e12556. doi: 10.14814/phy2.12556

Turner, A. J., and Trudinger, B. J. (2009). A modification of the uterine artery restriction technique in the guinea pig fetus produces asymmetrical ultrasound growth. Placenta 30, 236-240. doi: 10.1016/j.placenta.2008.11.023

van Abeelen, A. F., de Rooij, S. R., Osmond, C., Painter, R. C., Veenendaal, M. V., Bossuyt, P. M., et al. (2011). The sex-specific effects of famine on the association between placental size and later hypertension. Placenta 32, 694-698. doi: 10.1016/j.placenta.2011.06.012

Varma, D. R., and Ramakrishnan, R. (1991). Effects of protein-calorie malnutrition on transplacental kinetics of aminoisobutyric-acid in rats. Placenta 12, 277-284. doi: 10.1016/0143-4004(91)90009-5

Vaughan, O. R., Fisher, H. M., Dionelis, K. N., Jefferies, E. C., Higgins, J. S., Musial, B., et al. (2015a). Corticosterone alters materno-fetal glucose partitioning and insulin signalling in pregnant mice. J. Physiol. 593, 1307-1321. doi: 10.1113/jphysiol.2014.287177

Vaughan, O. R., Phillips, H. M., Everden, A. J., Sferruzzi-Perri, A. N., and Fowden, A. L. (2015b). Dexamethasone treatment of pregnant F0 mice leads to parent of origin-specific changes in placental function of the F2 generation. Reprod. Fertil. Dev. doi: 10.1071/RD14285. [Epub ahead of print].

Vaughan, O. R., Sferruzzi-Perri, A. N., Coan, P. M., and Fowden, A. L. (2012a). Environmental regulation of placental phenotype: implications for fetal growth. Reprod. Fertil. Dev. 24, 80-96. doi: 10.1071/RD11909

Vaughan, O. R., Sferruzzi-Perri, A. N., Coan, P. M., and Fowden, A. L. (2013). Adaptations in placental phenotype depend on route and timing of maternal dexamethasone administration in mice. Biol. Reprod. 89, 1-12. doi: 10.1095/biolreprod.113.109678

Vaughan, O. R., Sferruzzi-Perri, A. N., and Fowden, A. L. (2012b). Maternal corticosterone regulates nutrient allocation to fetal growth in mice. J. Physiol. 590, 5529-5540. doi: 10.1113/jphysiol.2012.239426

Vickers, M. H., Breier, B. H., Cutfield, W. S., Hofman, P. L., and Gluckman, P. D. (2000). Fetal origins of hyperphagia, obesity, and hypertension and postnatal amplification by hypercaloric nutrition. Am. J. Physiol. Endocrinol. Metab. 279, E83-E87.

Vickers, M. H., Clayton, Z. E., Yap, C., and Sloboda, D. M. (2011). Maternal fructose intake during pregnancy and lactation alters placental growth and leads to sex-specific changes in fetal and neonatal endocrine function. Endocrinology 152, 1378-1387. doi: 10.1210/en.2010-1093

Vieau, D., Sebaai, N., Leonhardt, M., Dutriez-Casteloot, I., Molendi-Coste, O., Laborie, C., et al. (2007). HPA axis programming by maternal undernutrition in the male rat offspring. Psychoneuroendocrinology 32 (Suppl. 1), S16-S20. doi: 10.1016/j.psyneuen.2007.03.014
Vieira-Filho, L. D., Lara, L. S., Silva, P. A., Luzardo, R., Einicker-Lamas, M., Cardoso, H. D., et al. (2009). Placental oxidative stress in malnourished rats and changes in kidney proximal tubule sodium ATPases in offspring. Clin. Exp. Pharmacol. Physiol. 36, 1157-1163. doi: 10.1111/j.1440-1681.2009.05212.x

Wadley, G. D., McConell, G. K., McConell, G. K., Siebel, A. L., Westcott, K. T., and Wlodek, M. E. (2013). Growth restriction in the rat alters expression of metabolic genes during postnatal cardiac development in a sex-specific manner. Physiol. Genomics 45, 99-105. doi: 10.1152/physiolgenomics.00095.2012

Wadley, G. D., Siebel, A. L., Cooney, G. J., McConell, G. K., Wlodek, M. E., and Owens, J. A. (2008). Uteroplacental insufficiency and reducing litter size alters skeletal muscle mitochondrial biogenesis in a sex-specific manner in the adult rat. Am. J. Physiol. Endocrinol. Metab. 294, E861-E869. doi: 10.1152/ajpendo.00037.2008

Wakefield, S. L., Lane, M., and Mitchell, M. (2011). Impaired mitochondrial function in the preimplantation embryo perturbs fetal and placental development in the mouse. Biol. Reprod. 84, 572-580. doi: 10.1095/biolreprod.110.087262

Walton, S. L., Singh, R. R., Tan, T., Paravicini, T. M., and Moritz, K. M. (2015). Late gestational hypoxia and a postnatal high salt diet programs endothelial dysfunction and arterial stiffness in adult mouse offspring. J. Physiol. doi: 10.1113/JP271067. [Epub ahead of print].

Wang, C., Li, H., Luo, C., Li, Y., Zhang, Y., Yun, D., et al. (2015). The effect of maternal obesity on the expression and functionality of placental P-glycoprotein: implications in the individualized transplacental digoxin treatment for fetal heart failure. Placenta 36, 1138-1147. doi: 10.1016/j.placenta.2015.08.007

Watkins, A. J., Lucas, E. S., Marfy-Smith, S., Bates, N., Kimber, S. J., and Fleming, T. P. (2015). Maternal nutrition modifies trophoblast giant cell phenotype and fetal growth in mice. Reprod. Suppl. 149, 563-575. doi: 10.1530/REP-14-0667

Watkins, A. J., Ursell, E., Panton, R., Papenbrock, T., Hollis, L., Cunningham, C., et al. (2008). Adaptive responses by mouse early embryos to maternal diet protect fetal growth but predispose to adult onset disease. Biol. Reprod. 78, 299-306. doi: 10.1095/biolreprod.107.064220

Wattez, J. S., Delahaye, F., Barella, L. F., Dickes-Coopman, A., Montel, V., Breton, C., et al. (2014). Short- and long-term effects of maternal perinatal undernutrition are lowered by cross-fostering during lactation in the male rat. J. Dev. Orig. Health Dis. 5, 109-120. doi: 10.1017/S2040174413000548

Wlodek, M. E., Mibus, A., Tan, A., Siebel, A. L., Owens, J. A., and Moritz, K. M. (2007). Normal lactational environment restores nephron endowment and prevents hypertension after placental restriction in the rat. J. Am. Soc. Nephrol. 18, 1688-1696. doi: 10.1681/ASN.2007010015

Wlodek, M. E., Westcott, K., Siebel, A. L., Owens, J. A., and Moritz, K. M. (2008). Growth restriction before or after birth reduces nephron number and increases blood pressure in male rats. Kidney Int. 74, 187-195. doi: 10.1038/ki. 2008.153

Wlodek, M. E., Westcott, K. T., O’Dowd, R., Serruto, A., Wassef, L., Moritz, K. M., et al. (2005). Uteroplacental restriction in the rat impairs fetal growth in association with alterations in placental growth factors including PTHrP. Am. J. Physiol. Regul. Integr. Comp. Physiol. 288, R1620-R1627. doi: 10.1152/ajpregu.00789.2004

Wu, L. L., Russell, D. L., Wong, S. L., Chen, M., Tsai, T. S., St John, J. C., et al. (2015). Mitochondrial dysfunction in oocytes of obese mothers: transmission to offspring and reversal by pharmacological endoplasmic reticulum stress inhibitors. Development 142, 681-691. doi: 10.1242/dev.114850

Zamudio, S. (2003). The placenta at high altitude. High Alt. Med. Biol. 4, 171-191. doi: $10.1089 / 152702903322022785$

Conflict of Interest Statement: The authors declare that the research was conducted in the absence of any commercial or financial relationships that could be construed as a potential conflict of interest.

Copyright (c) 2016 Sferruzzi-Perri and Camm. This is an open-access article distributed under the terms of the Creative Commons Attribution License (CC BY). The use, distribution or reproduction in other forums is permitted, provided the original author(s) or licensor are credited and that the original publication in this journal is cited, in accordance with accepted academic practice. No use, distribution or reproduction is permitted which does not comply with these terms. 